NBER WORKING PAPER SERIES

UNCERTAINTY OVER CAUSATION

AND THE DETERMINATION OF CIVIL LIABILITY

Steven Shavell

Working Paper No. 1219

NATIONAL BUREAU OF ECONOMIC RESEARCH

1050 Massachusetts Avenue

Cambridge, MA 02138

October 1983

The research reported here is part of the NBER's research program in Law and Economics. Any opinions expressed are those of the author and not those of the National Bureau of Economic Research. 
NBER Working Paper 非1219

October 1983

\author{
Uncertainty Over Causation and \\ The Determination of Civil Liability
}

\begin{abstract}
$\underline{\text { ABSTRACT }}$
Situations in which there is uncertainty over the cause of harm are studied (e.g., was the lung cancer due to normal exposure to medical $x$-radiation, to smoking, to exposure to carcinogens discharged by a chemical plant?); and the effects on incentives to reduce risk of various ways of treating such uncertainty under the liability system are identified using a theoretical model of the occurrence of harm. The main points are these. Use of a threshold probability of causation (e.g., 50\%) as a criterion for determining liability may adversely affect behavior: parties might face a diminished burden of liability (if their probability of causation systematically fell below the threshold) and thus do too little to reduce risk; or they might face an extra burden (if their probability were systematically above the threshold), and thus do too much. second, the best all or nothing criterion for determining liability (a criterion under which a party is fully liable if at all liable) is different in form from a threshold probability criterion. Third, liability in proportion to the probability of causation is superior to all other criteria and results in socially ideal behavior.

These points are demonstrated and analyzed in two types of case: where the uncertainty involves a party versus natural or "background" factors; and where it involves which party among several was the author of harm. The importance of the points is shown to depend on the type of case, and as well on the form of liability (strict liability or the negligence rule).
\end{abstract}

The interpretation of the analysis and important qualifications to it are discussed in a concluding section.

Steven Shavel1

Harvard Law School

Langde11 260

Cambridge, MA 02138

617-495-7920 
NBER Working Paper $\# 1219$

October 1983

\author{
Uncertainty Over Causation and \\ The Determination of Civil Liability
}

ABSTRACT

Situations in which there is uncertainty over the cause of harm are studied (e.g., was the lung cancer due to normal exposure to medical $x$-radiation, to smoking, to exposure to carcinogens discharged by a chemical plant?); and the effects on incentives to reduce risk of various ways of treating such uncertainty under the liability system are identified using a theoretical model of the occurrence of harm. The main points are these. Use of a threshold probability of causation (e.g., 50\%) as a criterion for determining liability may adversely affect behavior: parties might face a diminished burden of liability (if their probability of causation systematically fell below the threshold) and thus do too little to reduce risk; or they might face an extra burden (if their probability were systematically above the threshold), and thus do too much. second, the best all or nothing criterion for determining liability (a criterion under which a party is fully liable if at all liable) is different in form from a threshold probability criterion. Third, liability in proportion to the probability of causation is superior to all other criteria and results in socially ideal behavior.

These points are demonstrated and analyzed in two types of case: where the uncertainty involves a party versus natural or "background" factors; and where it involves which party among several was the author of harm. The importance of the points is shown to depend on the type of case, and as well on the form of liability (strict liability or the negligence rule).

The interpretation of the analysis and important qualifications to it are discussed in a concluding section.

Steven Shavel1

Harvard Law School

Langdel1 260

Cambridge, MA 02138

617-495-7920 


\section{Uncertainty Over Causation and the Determination of Civil Liability}

\section{S. Shave $11^{\star}$}

What is the importance to the working of the liability system of the possibility of uncertainty over the cause of accidents ${ }^{1}$ What is the importance, for example, of the possibility that it will not be known which of two hunters fired the shot that struck another; that it will not be clear whether the carcinogenic substance discharged from a chemical plant or normal exposure to medical $x$-radiation and other risks caused an individual's lung cancer; that it will not be easy to say whether a surgeon's careless use of a medical instrument, a nurse's mishandling of it, or a defect in its manufacture was responsible for a patient's injury? ${ }^{l a}$ The present article will employ a theoretical model of the occurrence of accidents and of the effect of liability on behavior to study such questions. It will be assumed for simplicity in this model that parties act solely in their financial self-interest. Moreover, because the chief concern will be with the desirability of the incentives created to reduce accident risks, it will be supposed that the measure of social welfare depends only on the value of engaging in risky activities, on accident losses, and on prevention costs. ${ }^{2}$ 
The conclusions reached in the model derive in essence from the familiar notion that for parties to be led to reduce accident risks appropriately, they should generally face probability-discounted or "expected"2a liability equal to the increase in expected losses that they create. (This, of course, is naturally the case in the absence of the chance of uncertainty over causation, for parties then face liability if and only if they cause losses.) The conclusions that will be obtained may be summarized by three statements.

(i) The use of a threshold probability as a criterion for the determination of liability in cases where causation is ambiguous has potentially adverse effects on behavior. (According to this criterion, only if the probability that a party caused an accident exceeds the threshold will the relevant liability rule be applied; the usual more-probablethan-not test ${ }^{3}$ thus involves a threshold of $50 \%$ ) ) Under any threshold probability, two types of problem may arise. On the one hand, a party's probability of causation in ambiguous cases might be systematically less than the threshold, with the result that he would escape liability in such cases, that is, face a diminished burden of liability, and thus might be inappropriately led to engage in risky activity or might fail to take desirable steps to reduce risk. On the other hand, a party's probability of causation in ambiguous cases might systematically exceed the threshold, meaning that he would always face liability in such cases, creating, 
in other words, an extra burden of liability, and thus the opposite difficulties.

(ii) The best all-or-nothing criterion for determination of liability is different in form from a threshold probability criterion. (An all-or-nothing criterion is any criterion for deciding whether the relevant liability rule shall be applied which preserves the usual feature of liability--that a liable party must pay damages fully equal to the injured party's losses. A threshold probability is thus an example of an all-or-nothing criterion.) The best all-ornothing criterion takes into implicit account not only the probability of causation but also the magnitude of losses and the effect of liability on deterrence. 3 a The criterion, however, does suffer from the same two types of defect as the threshold probability criterion (though to a lesser degree).

\section{(iii) Liability in proportion to the probability of} causation would be superior to the best all-or-nothing criterion and, thus, in particular, to any threshold probability criterion. (According to the proportional approach, the relevant rule of liability will always be applied, but the measure of damages will be set equal to the harm done multiplied by the probability that the liable party caused the harm.) Indeed, use of the proportional approach eliminates in the model all problems due to uncertainty over causation; it results in parties' facing expected liability equal to the expected losses they impose and thus it leads to socially desirable behavior. $3 b$ 
These points will be developed in two types of situation. In Part I of the article, the attention will be with situations where the uncertainty is whether the harm was caused by a party or by natural or "background" factors (the chemical plant vs. normal exposure to medical $x$-radiation and the like). And in Part II, the interest will be with situations where the uncertainty involves which party among several was the author of harm (one hunter vs. another, the surgeon vs. the nurse vs. the manufacturer); in this Part the interest will also be with whether the parties act independently or in concert. Significant differences will be shown to exist in the importance of the three main points in Parts I and I depending on the form of liability (either strict liability or the negligence rule). $3 c$

The article will conclude first with comments on the positive interpretation of the analysis--attempting to explain why a fixed threshold probability test has in fact been employed, subject only to certain exceptions. Then brief remarks will be made on the normative implications of the analysis--noting situations in which proportional liability may have appeal (chiefly, where the likelihood of uncertainty over causation is substantial, as in the area of many environmental and health related risks), and reflecting on the relevance of normative criteria that are not considered in the analysis (administrative costs, compensation of victims, fairness, costs of error). Following this will be an appendix formally stating and proving the claims of the text. 
I. Uncertainty Over Causation: Party versus Natural Agent Suppose that if and only if a party engages in a risky activity might he cause accidents, that a natural agent will cause accidents with some (fixed) probability ${ }^{4}$ regardless of whether the party engages in the activity, and that accidents will never be caused by both the party and the natural agent. 5

Additionally, assume that if the party engages in the activity, accidents might be correctly identified as due to him or as due to the natural agent; but they might also be seen as of ambiguous origin, in which case the probability that the party caused the accident will be determined. If the party does not engage in the activity, assume that all accidents will be correctly identified as due to the natural agent.

With regard to the legal system, assume that if an accident is known to be due to the party, a liability rule will be applied in the usual way; that if the accident is known not to be due to the party, he shall of course not be liable; that in ambiguous cases, either some (all-or-nothing) criterion will be used to decide whether the liability rule will apply, or else the liability rule will definitely apply but with the measure of damages being computed in proportion to the party's probability of causation.

Further, suppose that the party acts to maximize his expected position, namely, the value or benefit to him of engaging in his activity (should he do so), less the cost of care (should he take care), and less his expected liability. 
Finally, assume that social welfare is measured by the value to the party of engaging in his activity, less any cost of care, and less expected accident losses (comprised of losses caused by the party and those caused by the natural agent).

Let us now proceed to the analysis, examining first a "basic" model in which the party decides only whether to engage in his activity, and then an "extended" model in which he decides also whether to take care. The reason for studying both models is that while the main points are most easily seen from the basic model, important insights are gained by examining the more realistic version of the model in which care is a variable (in part, because only then can the negligence rule be analyzed).

A. Basic model: party decides only whether to engage in his activity.

In this version of the model, socially desirable behavior is easily described: the party ought to engage in the risky activity if and only if his benefits would exceed the increment he would cause in expected accident losses.

Example 1. The loss due to an accident would be 1,000; the risk of accidents due to the natural agent is $10 \%$; the additional risk were the party to engage in his activity would be $30 \%$. As the expected accident losses due to the party's engaging in his activity would be 300 (that is, $30 \% \times 1000$ ), it is socially desirable for him to engage in it if and only if his benefits would exceed 300. (Notice that the expected losses of 100 (that is, $10 \% \times 1000$ ) caused by the natural agent do not affect the ${ }_{6}$ desirability of the party's engaging in his activity. ${ }^{6}$ 
Let us now examine how the party would actually behave under the various approaches to treatment of uncertainty over causation, assuming liability to be strict. 7

threshold probability criterion. Because the party will be liable for losses in ambiguous cases under this criterion when and only when his probability of causation exceeds the threshold, the two problems stated in the introduction will clearly arise. Consider first the possibility that the party's probability of causation in ambiguous cases would exceed the threshold.7a In this event, the party's expected liability would indeed involve an extra burden, for it would include a component of accident losses due to the natural agent. Hence, the party might undesirably decide against engaging in his activity; and that would be so if his benefit would not exceed the increment in losses he would cause but by more than the extra burden.

Example 2a. Suppose the situation to be as in the previous example and suppose further that were the party to engage in his activity, $2 / 3$ of all accidents caused by him and $1 / 2$ of all accidents caused by the natural agent would be seen as ambiguous. Then there would be a $25 \%$ chance (that is, $2 / 3 \times 30 \%+1 / 2 \times 10 \%$ ) of accidents of ambiguous origin; an $80 \%$ probability of causation by the party in such accidents (for $20 \%$ is the risk of an ambiguous accident truly caused by the party, $5 \%$ is the risk of an ambiguous accident truly caused by the natural agent, and $20 \% /(20 \%+5 \%)=80 \%)$; a $10 \%$ chance (that is, $1 / 3 \times 30 \%$ ) of an accident known to be due to the party; and a $5 \%$ chance (that is, $1 / 2 \times$ $10 \%$ ) of an accident known to be due to the natural agent.

Thus, under, say, the more-probable-than not criterion, 8/ the party would be liable in ambiguous cases. His expected liability would therefore be 350 (that is, $(25 \%+10 \%) \times 1000)$. As 350 exceeds the expected accident losses he causes of 300 , his extra burden of liability is 50. Hence, he might undesirably be discouraged from engaging in the activity; and this would occur when his benefits are between 300 and 350 , that is, greater than 300 but not by more than the extra burden. 
Now consider the possibility that the party's probability of causation in ambiguous cases would fall below the threshold. Because the party would then bear a reduced burden of expected liability were he to engage in his activity, he might do so when it is socially undesirable.

Example 2b. Suppose instead that only $1 / 5$ of accidents caused by the party but $3 / 4$ of accidents caused by the natural agent would be seen as ambiguous. Then there would be a $13.5 \%$ chance (that is, $1 / 5 \times 30 \%+3 / 4 \times 10 \%$ ) of accidents of ambiguous origin; a $44.44 \%$ probability of causation by the party in such accidents (for $6 \% / 13.5 \%$ $=44.44 \%) ;$ a $24 \%$ chance of an accident known to be caused by the party; and a $2.5 \%$ chance of an accident known to be due to the natural agent. Hence, under the more-probable-than-not criterion, the party would not be liable in ambiguous cases and his expected liability would be only 240 . As a result of this diminished burden, the party might undesirably be led to engage in his activity; and that would be so when his benefits are between 240 and 300 .

It should be clear from the logic of Examples $2 \mathrm{a}$ and $2 \mathrm{~b}$ that both types of problem can arise for any level of the probability threshold between $0 \%$ and $100 \%$; there is nothing special about the more-probable-than-not threshold of $50 \%$.

best all-or-nothing criterion. That this does not take the form of a threshold probability criterion should be clear on reflection. Given the probability of causation, plainly it should matter what for instance are the party's benefits, as this will determine whether the party would be led to make an undesirable decision if he were or were not held liable. Hence the best decision of the court must depend on factors in addition to the probability of causation.

Example 3. Suppose the situation to be as described in Example 2a, where, recall, the probability of causation was $80 \%$; expected losses truly caused by the party's engaging in his activity were 300 ; and the party's 
expected liability would be 350 if he were held liable in ambiguous cases but would be only 100 otherwise. In this situation, an all-or-nothing determination about liability in ambiguous cases may be seen as a decision either to impose expected liability of 350 on the party--by holding him responsible in ambiguous cases--or as a decision to impose expected liability of only 100 on him--by holding him responsible only in cases where he is known to have caused harm.

What should the court do if it wishes to maximize social welfare? What, in other words, is the best all-or-nothing determination about liability? The answer depends on (among other factors) $9 /$ the court's estimate of the benefits that parties like the one with whom it is presented derive from engaging in their activities. Suppose, for instance, that the estimate is that most such parties would derive benefits between 300 and 350, and very few between 100 and 300 . Then, most parties would be undesirably discouraged from engaging in their activities were there liability in ambiguous cases, whereas few would be undesirably encouraged to engage in their activities were there no liability in ambiguous cases. Hence, the best decision would be not to hold the given party liable in ambiguous cases.

On the other hand, suppose the reverse to be the case, that the estimate is that most parties like the given one would enjoy benefits between 100 and 300 , and few between 300 and 350 . Then analogous reasoning leads to the conclusion that the best decision would be to hold the party liable in ambiguous cases.

We have therefore shown that the socially desirable decision

whether to hold the party liable in ambiguous cases may indeed depend on factors distinct from the probability of causation. But note that even given this best decision, there will still be some possibility of undesirably encouraging engagement in the activity or of undesirably discouraging it. 10 This is because it is in the nature of the all-ornothing approach that parties will either bear an extra burden of liability or a diminished one; they will never bear a burden that equals the increment in losses that they cause. 
proportional approach. If, however, liability in

ambiguous cases is made proportional to the party's probability of causation, the fundamental difficulty of the all-or-nothing approach that was just noted will be avoided. As is probably clear on intuitive grounds, under the proportional approach the party's expected liability will equal the increment in expected losses that he causes. He will therefore choose to engage in his activity precisely when his benefits are larger than these losses, which is to say, precisely in the socially desirable circumstances.

Example 4. Consider again the situation described in Example 2 a. Then, as the probability of causation would be $80 \%$ in ambiguous cases, the party's liability under the proportional approach would be 800 (that is, $80 \% \times 1000$ ) in such cases. His expected liability were he to engage in the activity would thus be equal to the sum of his expected liability from ambiguous cases, or $25 \% \times 800$, and his expected liability from cases known to be caused by him, or $10 \% \times 1000$; the sum is evidently 200 $+100=300$, which is the expected accident losses that he would cause.

Now suppose that the figures are altered as in Example 2b, where, recall, there was a $24 \%$ chance of accidents known to be caused by the party, a $13.5 \%$ chance of accidents of ambiguous origin, and in such cases a $44.44 \%$ probability of causation. Then, again, the party's expected liability under the proportional approach would equal 300 (that is, $13.5 \% \times 444.44+24 \%$ $\mathrm{x} 1000=60+240$ ) were he to engage in his activity.

This example illustrates that under the proportional approach the party's expected liability will equal expected losses due to his activity regardless of what would be the magnitude of his probability of causation. ${ }^{11}$ 
B. Extended model: party decides whether to engage in his activity and, if so, whether to take care.

Assume now that if the party engages in his activity, he may reduce the likelihood of an accident by taking care, which will involve a cost to him. The party's exercise of care will be socially desirable if the reduction in expected accident losses it would accomplish would exceed its cost. Moreover, whether his exercise of care would be desirable will influence the desirability of the party's engaging in his activity in the first place. specifically, if his exercise of care would be desirable, then the party's engaging in his activity will be desirable if his benefits would exceed the cost of care plus the (reduced level of) expected accident losses; but if his exercise of care would not be desirable, then his engaging in his activity will be desirable only if his benefits would exceed the (initial level of) expected accident losses.

Example 5. Modify Example 1 by assuming that if the party engages in his activity and takes care, the risk he causes will fall from $30 \%$ to $28 \%$. Thus, care would result in a reduction of 20 (that is, $2 \% \times 1000$ ) in expected accident losses, so that care ought to be taken if its cost is less than 20. Thus, if the cost of care is 10, it should be exercised if the party engages in his activity; and the party ought to engage in his activity in this case if his benefits would exceed $10+280=290$. But if the cost of care is 25, it should not be exercised by the party; and therefore he ought to engage in his activity only if his benefits would exceed 300 .

With this example in mind, let us reexamine the legal treatment of uncertainty over causation, first under strict 
liability and then under the negligence rule. (And in doing so, let us focus attention on the decision about the exercise of care given that the party chooses to engage in his activity, for the latter choice generally may be understood from what was said about it in the basic model.)

1. situation under strict liability

threshold probability criterion. Under this criterion, the party's decision about care will be socially appropriate if his probability of causation in ambiguous cases would exceed the threshold whether or not he takes care. To see why, notice that the party would then bear an extra burden of liability whether or not he takes care; thus his savings in expected liability from the exercise of care would equal the reduction thereby accomplished in expected accident losses; accordingly, and desirably, he will take care if and only if its cost is less than the reduction in expected accident losses.

Example 6a. Consider again the previous example where care would reduce the risk of accidents from $30 \%$ to $28 \%$; and suppose as in Example $2 a$, that $2 / 3$ of accidents caused by the party and $1 / 2$ of accidents caused by the natural agent would be seen as ambiguous. Then the party's probability of causation in ambiguous cases would be $80 \%$ if he does not take care and it would be $78.87 \%$ if he does.12/ Hence, under the more probablethan-not criterion, he would be liable in ambiguous cases and bear an extra burden of liability of 50 whether or not he takes care. In consequence, his expected liability will be $280+50=330$ if he takes care, $300+50=350$ if he does not, so that he will take care if and only if its cost is less than 20, the desirable result.

It should be clear, however, that the desirability of the decision over care here illustrated would not hold if the 
party's probability of causation might not exceed the threshold. In this regard, there are two possibilities. One is that the party's probability of causation would not exceed the threshold if he takes care--so he would bear only a diminished burden of liability--but his probability of causation would exceed the threshold if he fails to take care--so he would bear an extra burden. In this event, the party's savings in expected liability from taking care would be greater than society's savings of the decline in expected accident losses; for the party's savings would equal not only the decline in expected accident losses but also avoidance of the extra burden and the "gain" of the diminished burden. Hence, the party might take care when that would not be desirable.

Example 6b. Suppose that by the exercise of care, the party would reduce the risk of accidents from $30 \%$ to $6 \%$. Then while if he does not take care, his probability of causation in ambiguous cases would be $80 \%$, if he takes care it will be only $44.44 \%, 13 /$ which is below the $50 \%$ threshold. As a consequence, although if he does not take care, the party's expected liability will be 350, if he takes care, it will be only $60-40=20$. Hence, his liability savings from taking care would equal $350-20=330$, whereas the savings in expected accident losses are only $300-60=240$. (The party's liability savings exceed society's savings in accident losses by $330-240=90$ because by taking care, he avoids the extra burden of 50 and also enjoys a reduced burden of 40 on account of escaping liability in the ambiguous cases truly caused by him.) It follows that the party might be undesirably led to take care; and this would happen when the cost of care exceeds 240 but is less than 330 .

By contrast, the other possibility of interest leads to too little incentive to take care. If the party's probability of causation would be less than the threshold whether or not he takes care, then he would escape liability in ambiguous 
cases whether or not he takes care. He would therefore not derive any savings in liability from a care-related decline in ambiguous cases truly caused by him; his savings in expected liability from taking care would be less than the decline in expected accident losses. Thus, he might fail to take care when he ought.

Example 6c. Suppose that the situation is more or less the reverse of that in the preceding example; suppose now that the risk caused by the natural agent is $30 \%$; that the risk caused by the party is 10\%; that he can reduce the risk from $10 \%$ to $8 \%$ by the exercise of care; and that $1 / 2$ of accidents caused by him and $2 / 3$ of those caused by the natural agent would be seen as ambiguous. Then as the party's probability of causation in ambiguous cases would be below the $50 \%$ threshold whether or not he takes care--namely, $20 \%$ if he does not take care and $16.66 \%$ if he does--he would never be liable in such cases. Hence, if he does not take care, his expected liability would be $100-50=50$, and if he does take care, it would be $80-40=40$. His liability savings from taking care would thus be 50 $40=10$, namely, only half the true reduction of 100 $80=20$ in expected accident losses accomplished by taking care. In consequence, the party might not take care when he ought; and this will be the case whenever the cost of care is greater than 10 but less than 20 .

This completes the analysis of the incentive to take care. ${ }^{14}$ To recapitulate, the incentive to take care will be inadequate if the probability of causation would be less than the threshold regardless of the exercise of care; the incentive will be excessive if the probability of causation would be less than the threshold only if care were taken; but the incentive will be appropriate if the probability of causation would always exceed the threshold.

best all-or-nothing criterion. Once again, this will generally be different from a threshold probability criterion, as should be apparent from the logic of the argument given 
earlier. (Note, however, that the best all-or-nothing criterion should be more complicated than earlier, as it now will implicitly take into account the effect of liability on the decision whether to take care as well as on whether to engage in the activity.)

proportional approach. Under the proportional approach, the party will make the appropriate decisions about the exercise of care and engagement in the risky activity. As explained before, under this approach the party's expected liability will equal the expected accident losses he causes; hence the reduction in liability that he will derive from the exercise of care will equal the reduction in accident losses thereby accomplished; he will therefore take care when that would be desirable, and so forth.

Example 7. Consider again the situation of Example 6c, where the party might not have taken care when he ought under the more-probable-than-not criterion, and suppose that proportional liability is imposed in ambiguous cases. Then if the party engages in his activity and does not take care, his probability of causation in ambiguous cases will be $20 \%$ and his expected liability, 100 (that is, $25 \% \times 200+5 \% \times 1000$ ); and if the party does take care, his probability of causation will be $16.66 \%$ and his expected liability, 80 (that is, $24 \% \times 166.6+$ $4 \% \times 1000)$. Thus the party will take care if and only if its cost is less than the savings of $100-80=20$ in expected liability costs; as this equals the savings in expected accident losses, his decision about care will indeed be socially desirable.

2. situation under the negligence rule

By definition of the negligence rule, the party will be held liable for losses in an accident that he caused if he failed to take "due care"; otherwise he will not be liable. 
Assume here that due care is determined in a socially ideal manner by the courts: There is a duty to take care if and only if the cost of care is less than the savings in expected accident losses in which care would result. Assume also that care is accurately perceived by the courts, and thus that there will be no possibility of legal mistake about this element of a case.

Before proceeding to the analysis, recall the fundamental fact that under the negligence rule, the party's motive to engage in his activity may be too great, quite apart from any problems due to uncertainty over causation. The reason that the party might engage in his activity when he ought not is simply that if he takes due care, he will escape liability for any accidents that he causes. This means that he will see as the cost of engaging in his activity merely the cost of exercising due care--rather than the higher and true social cost equal to the cost of due care plus the expected accident losses caused by his activity. ${ }^{15}$

Example 8. Consider the situation where the risk of accident losses caused by the party would be $30 \%$ if he does not take care and $28 \%$ if he does; where the cost of care is 10; but where there is no possibility of uncertainty over causation. Then, as the exercise of care would be socially worthwhile, the party would have to take care to avoid being found negligent. And, clearly, if the party were to engage in his activity, he would decide to take care: if he did so, his only costs would be 10, the cost of care; but if he did not, his expected liability would equal 300. As a consequence, although the party would, desirably, be induced to take care if were to engage in his activity, he would decide to engage in it whenever his benefits would exceed 10 . But it would be desirable that he engage in his activity only when his benefits would exceed $10+280=290$. 
It turns out that this problem of socially excessive incentives to engage in risky activity may be exacerbated by the possibility of uncertainty over causation. Suppose that the party inappropriately fails to take due care because he will not be liable in ambiguously caused cases. Then, ipso facto, his expected liability must be less than the cost of care; and hence the problem of his having an excessive incentive to engage in the activity must be worsened. 16

Having now stated the (only) point of interest about uncertainty over causation and the decision to engage in the activity under the negligence rule, let us examine the decision to take care.

threshold probability criterion. Under this criterion, the party will never have too great an incentive to take care. Although he might be subject to liability "too often"-because his probability of causation might always exceed the threshold--he may avoid liability by taking due care; being subject to liability for negligence too often does not mean that the party pays too much in damages; it means only that he has a specially strong motive to take due care.

However, the party might have too little incentive to take care. This possibility may arise when the party's probability of causation in ambiguous cases would be below the threshold, for then he would be subject to liability for negligence too infrequently.

Example 9. Suppose that the risk due to the natural agent is $30 \%$; that the risk caused by the party if he engages in his activity and does not take care is $3 \%$; that the party can reduce the risk to $1 \%$ by taking 
care; that the cost of care is 18 ; and that $1 / 2$ of all accidents caused by the party and $2 / 3$ of those caused the natural agent would be seen as of ambiguous origin. Then the party's probability of causation would be below the threshold whether or not he takes care--it would be $6.98 \%$ if he does not take care and $2.44 \%$ if he does; and the risk of an accident for which he would be known to be the cause would be $1.5 \%$ (that is, $1 / 2 \times 3 \%$ ) if he does not take care. Hence, if he does not take care, his expected liability for negligence will be 15; if he takes care, although he will never be found liable, he will have borne a cost of 18 in so doing; accordingly, he will not take care. Thus, despite the social desirability of spending 18 on care to reduce expected accident losses by $20=30-10$, the party will not do so. The difficulty is that the party is subject to liability only half as often as he ought to be.

This problem of failure to take care will arise only if the probability of escaping liability for negligence is quite high, that is, only if the likelihood of ambiguous cases is high relative to the total risk created. This is because the underlying incentive to take due care is strong under the negligence rule; for by taking due care, one avoids liability entirely (rather than--as under strict liability-merely lowering its expected magnitude). 17

best all-or-nothing criterion. As stated before, this criterion is superior to, different from, and more complicated than any threshold probability criterion.

proportional approach. Under this approach, as should be clear from what was said before, a negligent party's expected liability would equal the expected accident losses he causes. Hence if the party engages in his activity, he will be led to take due care.

Example 10. Suppose in Example 9 that proportional liability is imposed for negligence in ambiguous cases. Then if the party does not take care, as his probability of causation will be $6.98 \%$, his expected liability will 
be 30 (that is, $21.5 \% \times 69.8+1.5 \% \times 1000$ ). And since he can avoid this liability by taking care at a cost of 18, he will do so (in contrast to what he was led to do in Example 9).

The situation under the proportional scheme, evidently, is therefore exactly that which would obtain were there no possibility of uncertainty over causation; there will always be an appropriate incentive to take due care (and there will be an equivalent problem of excessive incentives to engage in the activity). 
II. Uncertainty Over Causation: Which of Several Parties Was The Author of Harm

Assume as in the previous part that each party may decide to engage in a risky activity; ${ }^{18}$ that accidents are always caused by some single party among those engaging in risky activities; that this responsible party might be identifiable to the courts; but, if not, that the accident will be seen as of ambiguous origin, in which case the probability of causation of each party will be determined.

with regard to the legal system, make the same assumptions as before, adding only that in cases of ambiguous causation where more than one party is held liable, damages might be apportioned in some way. ${ }^{19}$

Also, continue to assume that the behavior of each party is determined by maximization of his expected position, and consider both the assumption that parties act independently and that they act in concert. Under the first assumption, we will determine a so-called equilibrium, a situation such that no party has reason to alter his behavior, assuming that other parties will continue to act as they have been. And under the assumption that parties act in concert, we will determine their jointly preferred position, that which maximizes the sum of their expected positions. 20

Finally, assume the measure of social welfare to be much as before, namely, the sum (over all parties) of the value of engaging in activities, less the sum of any costs of care, and less expected accident losses. 
We consider first the basic model and then the version of the model with care a decision variable. The numerical examples illustrating the results will be limited to the situation where there are just two parties involved, the extension to the situation with more than two parties usually being obvious.

A. Basic model: parties decide only whether to engage in their activities.

In this case, socially ideal behavior is of course for a party to engage in his activity if and only if the benefits he would derive exceed the increment he would cause in accident losses over what others cause (rather than, as before, over what was attributable to the natural agent).

Example 11. Modify Example 1 by supposing that a party A would create a $30 \%$ risk of accidents and another party B (rather than a natural agent) would create a $10 \%$ risk of accidents. Then $A$ ought to engage in the activity if his benefits would exceed 300 , and $B$ if his benefits would exceed 100 .

Now let us examine the behavior of parties assuming liability to be strict.

threshold probability criterion. Suppose initially that parties act independently. Then the two problems identified in part I generally arise: First, certain parties might undesirably fail to engage in their activities; for were they to engage in their activities, they might find themselves bearing an extra burden of liability due to their liability for accident losses of ambiguous origin. And second, some parties might undesirably decide to engage in 
their activities; for were they to do so, they might bear

only a reduced burden of liability due to their escaping

liability in cases of ambiguous origin.

Example 12. Continuing with Example 11, and assuming the more-probable-than-not criterion, let us first show that a party might undesirably fail to engage in his activity. Specifically, let us show that A might fail to engage in his activity when he ought to engage in it because by doing so he would become liable in all ambiguous cases and thus bear liability for some accidents caused by $B$. Suppose that $2 / 3$ of accidents caused by $A$ and $1 / 2$ of those caused by $B$ would be seen as of ambiguous origin if both engaged in their activities; and suppose A's benefits from engaging would be 325 , and $B^{\prime} s, 125$. Then both parties ought to engage in their activities, but only $B$ would do so. To see why, let us consider three candidates for an equilibrium situation, namely, both $A$ and $B$ engaging in their activities, $A$ alone engaging in his activity, and $B$ alone doing so. If both engage in their activities, then $A$ will be liable for all ambiguous cases--for A's probability of causation will be $80 \%$ and $B^{\prime} s 20 \%$; A's liability will thus be 350 and $B^{\prime} s$ will be 50 ; $A^{\prime}$ 's net position will be 325-350 $=-25$, and $B^{\prime} s, 125-50=75$; hence A would withdraw, meaning that the situation could not be an equilibrium. Similarly, if $A$ alone engages in his activity, B will decide to engage in his activity as well, for as just observed, he would then enjoy net benefits of 75; hence this situation too could not be an equilibrium. However, $B$ alone engaging in his activity is an equilibrium situation, for he would enjoy net benefits of $125-100=25$; and $A$ would not decide to engage in his activity, for as observed, he would lose 25 by doing so.

Let us now show that a party might undesirably engage in his activity. If we alter the benefit figures from above, we will find that both $A$ and $B$ will engage in their activities when $B$ ought not to; $B$ will engage in his activity only because he will avoid liability for part of his accident losses by escaping liability in ambiguous cases; he will ride on the coattails of $A$. specifically, let A's benefits be 400 and B's, 75 . Then while $A$ ought to engage in his activity, B ought not. Yet it is plain that each engaging in his activity is an equilibrium, for each will derive positive net benefits; A's will be 400-350=50, and $B^{\prime}$ 's will be 75-50=25. B engages in his activity because his liability is 50 rather than the 100 in expected accident losses that he causes. 
The relative importance of the two problems just illustrated obviously depends on the size of the threshold probability and on the number of potential participants in activities that could cause accidents of ambiguous origin. We would expect, for instance, that the importance of the problem of undesirably encouraging engagement in activities would increase as the number of potential participants rises and also as the threshold rises, for each would conduce to the possibility that any given party's probability of causation would lie below the threshold.

How is what we have said about the threshold probability criterion affected if we suppose that parties act in concert rather than independently? Recall that when parties act in concert, they will wish to maximize the sum of net benefits-which here means that they will want a party to engage in his activity if the benefits he would derive exceed any increase in the sum of expected liabilities of the parties.

Now assume the situation to be such that whenever an ambiguous case arises, some party (or parties) would be held liable--because his probability of causation would exceed the threshold. (This assumption will be relaxed below.) Then the outcome when parties act in concert would be socially ideal. The reason is simply that under the assumption just made, the sum of parties' liabilities would necessarily equal the sum of accident losses; hence the increase in the sum of expected liabilities due to a party's engaging in his activity would equal the increase in expected accident 
losses; in consequence, a party would be allowed by the group acting in concert to engage in his activity precisely when his benefits would exceed the increase in expected accident losses he would cause.

Example 13. Let us verify that in the previous example, an optimal outcome would result were $A$ and $B$ to act in concert. (In that example, it was true that either $A$ or $B$ would be liable for ambiguous cases, so the assumption of present interest is satisfied.) When $A^{\prime}$ 's and B's benefits were 325 and 125 , respectively, it was socially desirable that each engage in his activity. And this is what they would now do. If each engages in his activity, their joint expected position will be $(325-350)+(125-50)=50$; if $A$ alone does so, their joint position will be only $325-300=25$; and if $B$ alone does so, it will also be 125-100=25; hence $A$ and $B$ will indeed be best off each engaging in his activity.21/ on the other hand, when $A$ 's and $B$ 's benefits were 400 and 75 , it was socially desirable that $A$ alone engage in his activity, and this is what would occur when the two parties act in concert. If each engages in his activity, their joint position will be (400-350) $+(75-50)=75$; if $\mathrm{A}$ alone engages in his activity, it will be 400-300 = 100; if $\mathrm{B}$ alone engages in his activity, it will be 75-100=-25; hence $A$ alone will engage in his activity. $22 /$

If we now alter the assumption that some party will be liable in each ambiguous case, then the outcome when parties act in concert may not be socially desirable; there will be a potential problem of parties' undesirably engaging in their activities. The reason in essence is that by engaging in their activities, parties might introduce enough uncertainty about ambiguous cases to make the probability of causation of each fall below the threshold, allowing them all to escape liability in such cases.

Example 14. A and B would each derive benefits of 75 from engaging in his activity; each would create a $10 \%$ risk of accidents by so doing; were each to engage in his activity, $1 / 2$ of accidents caused by each would be seen as of ambiguous origin--so that the probability of causation of each would be $50 \%$. 
In this situation, it would be best that neither $A$ nor $B$ engage in his activity, as each would cause expected accident losses of 100. Yet by agreeing jointly to engage in their activities, $A$ and $B$ would avoid half their liability--each would bear expected liability of only 50--for under the more-probable-than-not criterion, neither would be held liable in ambiguous cases. Hence, $A$ and $B$ would each derive net benefits of 75-50=25 and would, undesirably, engage in their activities.

Note, however, that the opposite problem--of too little engagement in activities--cannot arise because the sum of expected liability costs surely will not increase by more than the true addition to expected accident losses when a party engages in his activity.

best all-or-nothing criterion. For now familiar reasons, this criterion is different from and superior to a threshold probability criterion. (It would, for example, take into account whether parties acted in concert.)

proportional approach. This approach would again lead to socially ideal behavior, whether parties act independently or in concert. If the parties act independently, each would clearly be led to engage in his activity if and only if his benefits would exceed the expected accident losses he would cause, for under the proportional approach each party's expected liability would equal the expected accident losses he would cause. Similarly, if the parties act in concert, each would be led to engage in his activity exactly when that would be desirable; for the fact that each party's expected liability would equal his expected accident losses means that the increment in the sum of expected liabilities due to a party's engaging in his activity would equal the expected accident losses he would cause. 
B. Extended model: parties decide whether to engage in their activities and, if so, whether to take care.

The points of interest here can be explained without further numerical examples and largely by reference to previous discussion. (In any event, the situations to be considered will often involve so many elements that numerical examples would become too complicated to be helpful.)

1. situation under strict liability

We will discuss here only the decision to take care, as the conclusions from the basic model about engagement in the activities will carry over to the extended model.

threshold probability criterion. Suppose first that parties act independently. Then the situation is as described in part I. That is, a party might have an appropriate incentive to take care; and this would be so if his probability of causation would exceed the threshold whether or not he takes care. On the other hand, a party might have an incorrect incentive to take care: his incentive would be excessive if his probability of causation would fall below the threshold only if he takes care; and his incentive would be inadequate if his probability of causation would fall below the threshold whether or not he takes care.

Now suppose that parties act in concert. Then the conclusions depend on the two possibilities discussed in the basic model. The first, recall, was that some party (or parties) would be liable for losses in each ambiguous case. In this case, joint expected liability would equal actual 
joint expected accident losses; thus by logic similar to that given in the basic model, parties' incentives to take care would be socially ideal. The other possibility was that parties' joint liability might be less than expected accident losses since all might escape liability in ambiguous cases. In this circumstance, parties' incentives to take care would be inadequate, and some parties might fail to take care when they ought to.

best all-or-nothing criterion. Again, this is more complicated than and superior to a threshold probability criterion.

proportional approach. Because this results in each party's bearing the true expected accident losses he causes, it leads to ideal incentives to take care as well as to engage in risky activities, and regardless of whether parties act independently or in concert.

2. situation under the negligence rule

We will again discuss only the decision to take care. (Recall, however, that under the negligence rule there is an underlying problem of too great an incentive to engage in risky activities.)

threshold probability criterion. If the parties act independently, then their motive to take care will be as described in part I. Specifically, if a party's probability of causation would exceed the threshold if he took care, his motive to take care would be appropriate. But if his probability of causation would be below the threshold if he took care, 
his incentive to take care would be inadequate, as his expected liability for negligence would be too low.

Suppose, on the other hand, that parties act in concert. Then if some party (or parties) would be liable for negligence in each ambiguous case, parties would always be induced to take due care: as explained above, the joint potential expected liability for negligence would then equal the expected accident losses truly caused. But if all parties might escape liability for negligence in ambiguous cases, then some parties might not be induced to take due care. best all-or-nothing criterion. This is again different from and superior to a threshold probability rule.

proportional approach. This results in the exercise of due care in all circumstances, as expected liability for negligence would equal expected accident losses caused. 


\section{Concluding Comments}

In closing, let us consider briefly (a) the positive implications of the theoretical analysis--the consistency of the results obtained with the actual determination of liability in the face of uncertainty over causation; and (b) the normative implications of the analysis--the recommendations that are suggested by the results.

(a) On the issue of uncertainty over causation, the general approach of the law has been to make a liable defendant pay damages fully equal to any losses of which he was moreprobably-than-not the cause. ${ }^{23}$ For several reasons, this fact--that the law employs an all-or-nothing approach to liability based on a threshold probability--need not be seen as inconsistent with the theoretical superiority in the model of liability in proportion to the probability that the defendant caused losses. Most obviously, one would hardly expect as important an element of liability as its all-ornothing character to be abandoned in the face of this or that aspect of a case, here in the face of uncertainty over causation, unless there were strong reasons to do otherwise. And no strong reasons to do otherwise appear to exist in respect to the usual tort. In particular, one suspects that the likelihood of real uncertainty over the cause of the usual tort must be small, 24 and thus so must be the chance of any adverse behavioral consequences associated with the all-or-nothing character of liability and use of a threshold probability test. 25 (Further, the fact that the negligence 
rule is the major form of tort liability supplies other if subtle reasons for thinking that adverse effects on behavior are likely to be small.) ${ }^{26}$ Additionally, there are considerations going outside the model that appear to favor the usual approach over the alternative of proportional liability: as discussed below, the usual approach may result in fewer cases and lower administrative costs than the proportional and, further, be perceived as fair rather than unfair.

If, then, it seems understandable that liability has retained its all-or-nothing character in the typical case involving uncertainty over causation and that a threshold probability criterion has been employed, what can be said about the fact that the courts have occasionally chosen explicitly to adjust the magnitude of the threshold from $50 \% ?^{27}$ And what can be said about the view that this is often done implicitly, according to the felt requirements of policy and the nature of the case? ${ }^{27 a}$ The answer is that altering the threshold probability may be interpreted as reflecting the theoretical result that the best all-or-nothing criterion cannot be expressed as a fixed threshold probability criterion and that this best criterion generally depends on many characteristics of the particular problem at hand.

At the same time, it seems consistent with theory that in certain restricted types of case, the threshold requirement has in effect been dropped and, recently, that use of the proportional approach has been seriously considered and even adopted. For instance, when it was unclear which hunter fired the harmful shot, the court did not insist that the 
probability threshold requirement be met; instead it simply shifted the burden of proof about causation to defendants. 28 And where it was not ascertainable which company manufactured the generic drug that caused cancer, the court found companies liable according to their market share, that is, approximately in proportion to the probability that they caused harm.29,29a Such cases are distinguishable in the theoretically anticipated way: they raise in a vivid manner the possibility that there would be problematic effects associated with use of the usual approach to the determination of liability; ${ }^{29 b}$ for under the usual approach defendants would be allowed to go free even though the court knows with high probability that some one of them caused the harm. Indeed, this concern is sometimes expressed in opinions. 30

(b) The principal normative implications of the analysis follow from what we have just said. They are two. First, where little problem with adverse incentives would be expected to result from use of the usual approach in determining liability--that is, where the likelihood of uncertainty over causation would be low--there will be no special reason for change. Thus, surely, no change is recommended as a general matter.

But, second, where significant undesirable effects on behavior could result from use of the usual approach -where the chance of uncertainty over causation would be substantial -- adoption of some form of the proportional approach may have appeal. Perhaps the area in which this 


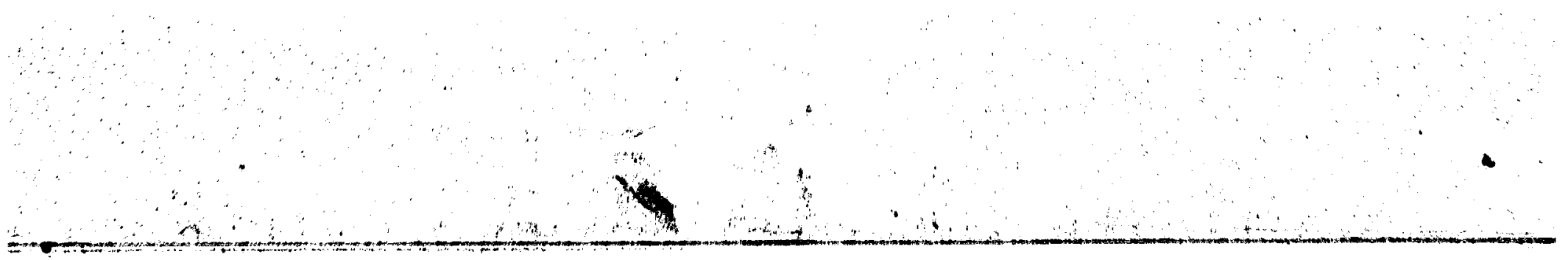


to be below the threshold, he will not be likely to initiate legal action under the threshold criterion but may well under the proportional approach. ${ }^{34}$ second, the likelihood that a suit would result in a trial would also seem to be larger under the proportional approach. This is because use of the proportional approach introduces as an additional issue of possible dispute between the parties the actual magnitude of the probability of causation. (Under the threshold probability criterion, by contrast, the actual magnitude of the probability will not be at issue except with respect to the question whether the probability is above or below the threshold. $)^{35}$ And third, the cost of a trial would as well seem greater under the proportional approach. This appears so again because of the introduction of the actual magnitude of the probability of causation (beyond the threshold determination) as an additional issue of potential dispute; because the jury too would now have to decide about the actual magnitude of the probability of causation; and because one would expect a greater number of defendants to be involved in the typical dispute (the plaintiff joining as defendants many of the parties who could conceivably have done him harm). In sum, then, not just the volume of disputes but also the probability that a dispute will result in a trial and the cost per trial would seem greater under the proportional approach.

With regard to the issue of compensation, the main observations to be made are that when the probability of causation does not exceed $50 \%$, the proportional approach 
results in positive compensation and the usual approach results in none; that when the probability of causation does exceed $50 \%$, the proportional approach results in less compensation than the usual approach; and that the former effect may be more important than the latter. 35 a cone may wonder, though, about the relevance of interest in the compensatory characteristics of the liability system given the availability of private insurance and the possibility of establishing social insurance programs.)

Concerning fairness, the principle that comes immediately to mind is that a party ought not be punished for a harm unless he did it, and--by extension--he ought not be punished for a harm unless we are reasonably sure he did it. This principle of fairness is in perfect accord with use of a threshold probability criterion in the determination of liability; on the other hand, the principle would be violated by use of proportional liability, as a party would suffer some sanction even when it was unlikely that he caused a harm. Yet in assessing the importance of this consideration favoring the threshold probability criterion, the analyst should take into account two limiting factors. First, the appeal of the principle seems strongest in the criminal context, where actual punishment is meted out; in the civil context, where the sanction is monetary and frequently paid by a liability insurer, the significance of adherence to the principle would seem diminished. Second, where the defendant parties are not individuals but (large) firms, the importance of the principle would also seem reduced. 
Finally, and closely related to the principle of fairness, is the goal of minimizing the costs of error. $36,36 a$ As Professor Kaye has recently shown, this goal implies the superiority of the more-probable-than-not rule over proportional liability. ${ }^{36 b}$ Now while normally one cannot object to study of a particular social goal on logical grounds, in the case of error minimization, one can. The objection is that whereas one presumes that a social goal ought to be based on immediate determinants of individual welfare, ${ }^{36 \mathrm{c}}$ the goal of error minimization is not; the goal is instead chiefly a proxy for the undesireable effects on individual welfare due to the consequences flowing from errors. It is these consequences that primarily matter to individual welfare, one supposes, and not the errors themselves. (It is whether an individual is affected by a carcinogen produced by firms and, if so, whether he is compensated that matters to an individual one would think, and not whether any firm has to pay damages when it was not the cause.) In strict logic, the only reason to include error as a direct ingredient of social welfare is a belief that error matters to individuals independent of the consequences due to error; and to the extent that this is thought significant, error should be introduced as a, not the, determinant of social welfare. The reader may tend to regard this distinction as over subtle, and admittedly in many contexts it will not be of any real importance; but it is sometimes of significance, and it does explain why the criterion of minimizing errors can lead to anomalies (such as that none of the firms producing the 
carcinogen should be liable since none is ever more-probablythan-not the cause). $36 d$ 


\section{Appendix}

As the general model has been discussed in the text, we will describe it here as briefly as possible.

(i) All outcomes are defined in terms of a single good to be called "wealth".

(ii) Social welfare equals the expected value of the sum of parties' wealth. (Equivalently, it will be seen to equal the value of engaging in activities less, possibly, the cost of care, and less expected accident losses.)

(iii) Parties are risk-neutral in wealth; they act so as to maximize its expected value.

(iv) Accidents--events involving a loss of wealth-occur with a probability depending on whether parties engage in risky activities and, possibly, on whether they take care. 37

(v) Each accident is caused by precisely one entity (a party or a natural agent), that is, there is one and only one entity for which the following statement is true: "The accident would not have occurred in the absence of the entity."

(vi) When an accident occurs, there will be a chance that the entity which caused it will not be known to the court; such instances will be said to be of ambiguous origin; but the conditional probability--the probability of causation-that the entity caused the accident will be determined by the court. 
(vii) Two types of legal treatment of cases of ambiguous origin will be investigated. The first involves the use of an all-or-nothing criterion, a function (of variables to be specified) determining whether the applicable liability rule (strict liability or negligence) shall be employed. The specific all-or-nothing criterion to which most attention will be paid is the threshold probability criterion, under which the applicable liability rule shall be employed if the probability of causation exceeds the threshold probability. The second type of treatment of ambiguous cases is to adopt use of proportional liability: always to employ the applicable liability rule, but to set the damages to be paid in the event of liability equal to the accident loss multiplied by the probability of causation.

We will now analyze versions of the general model (those considered in the text), amplifying on or adding to the assumptions just made as we proceed.

I. Uncertainty over Causation: Party vs. Natural Agent

A. Basic model: party decides only whether to engage in his activity

Define the following notation.

$v=$ value to the party of engaging in his activity; $v$ $\geqq 0$ ；

$\mathrm{p}=$ probability of accidents caused by the party's engaging in his activity; 


$$
\begin{aligned}
& \mathrm{n}=\text { probability of accidents caused by the natural } \\
& \text { agent; } 0<\mathrm{n}<1 ; \mathrm{p}+\mathrm{n} \leqq 1 ; \\
& \boldsymbol{\ell}=\text { loss if accident occurs; } \ell>0 .
\end{aligned}
$$

As the events that an accident is caused by the party and by the natural agent are mutually exclusive (assumption (v)), it is socially desirable for the party to engage in his activity if $37 a$

(1) $\mathrm{v}>\mathrm{p} \ell$.

If the party does not engage in his activity, then all accidents are assumed to be known to be due to the natural agent. 38 But if the party does engage in his activity, cases of ambiguous origin will arise, and to describe this, define

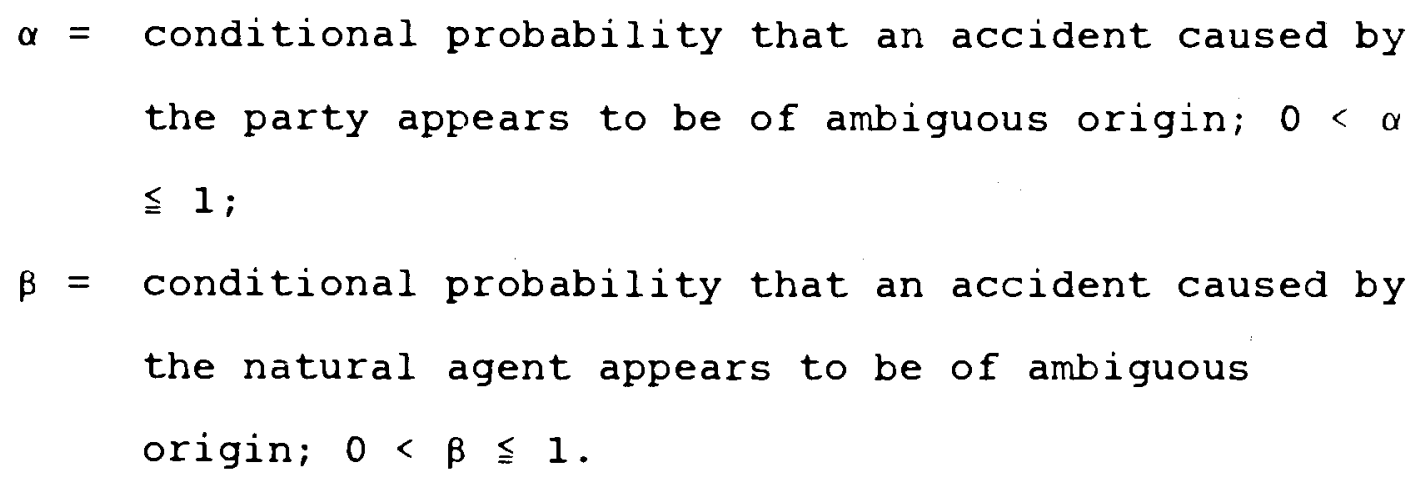
the party appears to be of ambiguous origin; $0<\alpha$ $\leqq 1 ;$

$\beta=$ conditional probability that an accident caused by the natural agent appears to be of ambiguous origin; $0<\beta \leqq 1$.

Hence, the probability of an accident known to be caused by the party will be

\section{(2) $p(1-\alpha)$;}

the probability of an accident caused by the party but seen as of ambiguous origin will be

\section{(3) $p \alpha$;}

the probability of an accident known to be caused by the natural agent will be 
(4) $n(1-\beta)$;

and the probability of an accident caused by the natural agent but seen as of ambiguous origin will be

(5) $\mathrm{n} \beta$.

Accordingly, the conditional probability that an accident of ambiguous origin was caused by the party, that is, the probability of causation, will be

(6) $c=p \alpha /(p \alpha+n \beta)$.

we remark that $c$ could equal any value in $(0,1) .39$

Let us assume that the applicable liability rule is strict liability, according to which a party would simply be liable for losses in the absence of uncertainty over causation. 40

Let us now examine the different ways of treating cases of ambiguous origin. In doing this we assume that the court knows (can "observe") the variables $p, n, \ell, \alpha$, and $\beta$, but that it cannot observe $v$. However, we assume that the court knows the probability distribution of $v$; let this be characterized by

$$
\begin{aligned}
f(\cdot)= & \text { probability density of the value } v \text { of engaging } \\
& \text { in the activity; } f \text { is positive over }[0, \bar{v}] \\
& \text { and zero elsewhere; } \bar{v}>\ell .
\end{aligned}
$$

Let us consider first the threshold probability criterion, where

$$
t=\text { threshold probability; } 0<t<1 \text {. }
$$

Under this criterion, in cases of ambiguous origin the party will be liable and pay $\ell$ in damages when 
(7) $c>t$.

(If the party is known to have caused an accident, then of course he also pays $\ell$ in damages. $)^{41}$ Let us now prove

Proposition 1. Use of the threshold probability criterion may lead to a socially undesirable outcome; the party might undesirably fail to engage in his activity or might undesirably engage in it.

Proof: If $c>t$ would hold in ambiguous cases, 42 the party will be liable in all such cases. Thus, his expected liability were he to engage in his activity would be 43

(8) $\mathrm{p}(1-\alpha) \ell+\mathrm{p} \alpha \ell+\mathrm{n} \beta \ell=\mathrm{p} \ell+\mathrm{n} \beta \ell$, so that he will engage in his activity if

(9) $v>p l+n \beta l$.

Comparing this to (1), we see that the party will not engage in his activity when it would be socially desirable that he didif $p \ell<v<p \ell+n \beta \ell$.

On the other hand, if $c \leqq t$ would hold in ambiguous cases, then the party will never be liable in such cases, so that his expected liability would be only ${ }^{44}$

(10) $p(1-\alpha) \ell=p \ell-p \alpha \ell$.

Hence, he will engage in the activity if

(11) $\mathrm{v}>\mathrm{pl}-\mathrm{p} \alpha \ell$,

implying that he will engage in the activity when that would be undesirable if $\mathrm{pl}-\mathrm{p}$ l $\ell<\mathrm{v}<\mathrm{pl}$. Q.E.D. 45 
Next, let us consider the best all-or-nothing criterion for determining liability in ambiguous cases. Under this criterion, the court uses all the information at its disposal--p, $n, \ell, \alpha, \beta$, and $f(\cdot)$--and determines whether there should be liability so as to maximize the expected value of social welfare. Specifically, if the court would not hold the party liable, then social welfare will be

$$
\text { (12) } \int_{\mathrm{p} \ell-\mathrm{p} \alpha \ell}^{\overline{\mathrm{v}}}(\mathrm{v}-\mathrm{p} \ell) f(\mathrm{v}) \mathrm{dv} \text {; }
$$

and if it would hold the party liable, then social welfare will be $\bar{v}$

(13) $\int(v-p \ell) f(v) d v$.

$p \ell+n \beta \ell$

Hence the court would hold the party liable when (13) exceeds (12), or, equivalently, when

$$
\text { (14) } \int_{p \ell}^{p \ell+n \beta l}(v-p \ell) f(v) d v<\int_{p \ell-p \alpha \ell}^{p \ell}(p \ell-v) f(v) d v .
$$

Note that the interpretation of the left-hand term in (14) is the "opportunity loss" that would be due to socially undesirable discouragement from the activity were there liability in ambiguous cases; and the interpretation of the right-hand term is the loss that would be due to socially undesirable engagement in the activity were there were not liability in ambiguous cases. Under the threshold probability criterion, by contrast, it is the size of $c=p \alpha /(p \alpha+n \beta)$ versus $t$ that determines whether there is liability--and $t$ is presumed to be fixed, not to depend on $\ell, p, n$, or other variables. 46 This suggests 
Proposition 2. The best all-or-nothing criterion is not equivalent to (and thus is superior to) a threshold probability criterion.

Note. The best all-or-nothing criterion may still lead to both types of socially undesirable outcome as are possible under a threshold probability criterion.

Proof: Assume that the best all-or-nothing criterion is equivalent to a threshold probability criterion for some $t$, say $t^{\prime}$, and consider for example a $p, n, \alpha$, and $\beta$ such that $c=p \alpha /(p \alpha+n \beta)>t^{\prime}$. Then the party would be liable under the threshold criterion, but he might not be liable under the best all-or-nothing criterion; for, clearly, (14) might not hold (suppose that most of the probability mass of $v$ is concentrated in the interval $(\mathrm{p} \ell, \mathrm{p} \ell+\mathrm{n} \beta \ell))$. Thus the assumption that the criteria are equivalent is contradicted. 47

Regarding the Note, it is obvious that both types of problem are possible depending on $p, n, \ell, \alpha, \beta$, and $f(\cdot)$ : for if (14) holds, then the party might be undesirably discouraged from engaging in the activity; and if (14) does not hold, then the party might be undesirably encouraged to engage in it. $\quad$ Q.E.D.

Last, let us consider proportional liability. Recall that under this approach, the party would pay cl in all cases of ambiguous origin. We have

Proposition 3. Use of proportional liability leads to a socially desirable outcome. 
Proof: If the party engages in his activity, his expected liability will be

$$
\begin{gathered}
\text { (15) } p(1-\alpha) \ell+(p \alpha+n \beta) c \ell=p(1-\alpha) \ell+ \\
(p \alpha+n \beta)[p \alpha /(p \alpha+n \beta)] \ell=p \ell .
\end{gathered}
$$

Hence, the party will engage in his activity when $v>p \ell$, which is precisely the condition (1). Q.E.D. ${ }^{48}$

B. Extended model: party decides whether to engage in his activity and, if so, whether to take care.

We will now consider the possibility that the party can reduce the probability of an accident by taking care. To this end, define

$$
\begin{aligned}
\mathrm{q}= & \text { probability of accidents caused by the party's } \\
& \text { activity if he takes care; } 0<\mathrm{q}<\mathrm{p} ; \text { and } \\
\mathrm{x}= & \text { cost of taking care; } 0<\mathrm{x} .
\end{aligned}
$$

Hence, if the party engages in his activity, it will be socially desirable for him to take care if

(16) $q \ell+x<p \ell$.

Further, if (16) holds, then it will be socially desirable for the party to engage in his activity if

$$
\text { (17) } v>q \ell+x ;
$$

but if (16) does not hold, (1) will as before determine the social desirability of his engaging in his activity. We will assume that the same conditional probabilities $\alpha$ and $\beta$ of accidents appearing ambiguous apply whether or not care is taken. 49 
Hence, if the party engages in his activity and takes care, the probability of an accident known to be caused by him will be

$$
\text { (18) } q(1-\alpha) \text {; }
$$

the probability of an accident caused by him but seen as of ambiguous origin will be

(19) $\mathrm{q} \alpha$;

if the party does not take care, the analogous probabilities will still be given by (2) and (3); and the analogous probabilities of accidents caused by the natural agent will still be given by (4) and (5). If the party takes care, his probability of causation in cases of ambiguous origin will be

$$
\text { (20) } \mathrm{c}=\mathrm{q} \alpha /(\mathrm{q} \alpha+\mathrm{n} \beta) \text {, }
$$

which, note, is lower than $c$ will be if he does not take care (as $q<p)$. Let us now proceed with the analysis, first assuming liability to be strict, and then to be based on the negligence rule.

1. situation under strict liability

We have

Proposition 4. Use of the threshold probability criterion may lead to a socially undesirable outcome. Specifically,

(a) the party might undesirably fail to engage in his activity or might undesirably engage in it;

(b) if the party engages in his activity, he might undesirably fail to take care or he might undesirably take care. 
Note. Part (a) is true for essentially the reason that Proposition 1 was true. With regard to (b), we will show (i) that the party might undesirably fail to take care precisely when $c \leqq t$ whether or not care is taken; (ii) that the party might undesirably take care precisely when $c \leqq t$ only if care is taken; and (iii) that the party will take care if and only if that is desirable precisely when $c>t$ regardless of whether care is taken.

Proof: (a) we omit the argument for this part, as it is analogous to that given in Proposition 1 .

(b) Assume that the party is induced to engage in the activity and consider in turn the three possibilities mentioned in the Note.

(i) $c \leqq t$ regardless of whether care is taken. In this case, expected liability is pl - pal if care is not taken and ql qae if it is, so that care will be taken if

$$
\text { (20) } \mathrm{q} \ell-\mathrm{q} \alpha \ell+\mathrm{x}<\mathrm{p} \ell-\mathrm{p} \alpha \ell
$$

or, equivalently, if

$$
\left(20^{\prime}\right) q \ell+x<p l-(p-q) a \ell .
$$

Comparing this to $(16)$ and noting that $(p-q) \alpha l>0$, it is evident that the party might undesirably fail to take care (but would not undesirably take care).

(ii) $c \leqq t$ only if care is taken. In this case, expected liability is $p \ell+n \beta \ell$ if care is not taken and it is ql - qal if it is, so care will be taken when

$$
\text { (21) } \mathrm{q} \ell-\mathrm{q} \alpha \ell+\mathrm{x}<\mathrm{p} \ell+\mathrm{n} \beta \ell
$$

or, if

$$
\left(21^{\prime}\right) q \ell+x<p l+(q \alpha+n \beta) \ell .
$$


Comparing this to $(16)$ and noting that $(q \alpha+n \beta) l>0$, it is evident that the party might undesirably take care (but would not undesirably fail to do so).

(iii) $c>t$ regardless of whether care is taken. In this case, expected liability is $p \ell+n \beta \ell$ if care is not taken and it is $q \ell+n \beta \ell$ if care is taken. Hence care will be taken if

(22) $q \ell+n \beta \ell+x<p \ell+n \beta \ell$, or if

(22') $q \ell+x<p \ell$,

which is just (16), so that care will be taken if and only if it is socially desirable. Q.E.D.

Proposition 5. The best all-or-nothing criterion is not equivalent to (and thus is superior to) a threshold probability criterion.

(The argument is analogous to that of Proposition 2 and is therefore omitted.)

Proposition 6. Use of proportional liability leads to a socially desirable outcome.

Proof. By the steps in (15), it is clear that if the party engages in his activity and does not take care, his expected liability will be pl; and if he does take care, it will be $q l$. Hence, if he engages in his activity, he will take care if $q \ell+x<p \ell$. But this is just (16), so that his decision about care will be socially desirable. Further, if he would wish to take care, then he will choose to engage 
in his activity when $v>q l+x$; and if he would not wish to take care, he will choose to engage in his activity when $v>$ pl. But these conditions are just (17) and (1), so that the party's decision whether to engage in the activity will also be socially desirable. Q.E.D.

2. situation under the negligence rule

We will assume that a party would be found negligent if and only if he undesirably failed to take care, that is, if and only if he failed to take care when (16) held; thus, we assume that when (16) does not hold, the party will never be found negligent. 50 If the party is found negligent, then under the negligence rule, he will be liable for the loss he has caused.

Let us review the properties of the negligence rule in the absence of uncertainty over causation (so that we can see what difference such uncertainty makes). Thus, let us assume in this paragraph that an accident would be seen to be caused by the party if and only if it truly was so caused. Now suppose the party has decided to engage in the activity and that the exercise of care is desirable. Then if the party failed to take care, he would be liable for all accidents he caused, implying that his expected liability would be pl; but he would never be liable if he took care. Hence, he will take care if $x<p \ell$. But, using (16),

(23) $x<q \ell+x<p \ell$, so that the party will indeed take care. On the other hand, if the exercise of care is not desirable, the party would 
never be found liable, so that he would not take care. We have therefore shown that the party will be induced to take care if and only if that would be desirable. However, the party will be led to engage in the activity too often: If taking care is desirable, then since he would be induced to do so and would never be liable, the party would decide to engage in the activity whenever

$$
\text { (24) } v>x
$$

rather than only when $v>q \ell+x$. And if taking care is not desirable, since he would never be liable and would not take care, he would engage in the activity whenever

$$
\text { (25) } v>0
$$

rather than only when $v>p \ell$.

With these facts in mind, let us proceed.

Proposition 7. Use of the threshold probability criterion may lead to a socially undesirable outcome. specifically,

(a) the problem of an excessive incentive to engage in the activity may be exacerbated; and

(b) if the party engages in his activity, he might undesirably fail to take care.

Note. The problem in (b) can arise only where $c \leqq t$ if care is not taken; and the problem in (a) can arise only where the problem in (b) would arise.

Proof. (a) Suppose that the exercise of care would be desirable if the party were to engage in his activity. Then if the party would be induced to take care were he to engage in his activity, he would decide to engage in it when $v>x$, which is just (24), so in this case the problem of excessive 
incentives to engage in the activity would not be worsened. However, if the party would not be induced to take care were he to engage in his activity, then (as will be explained in the proof to (b)) he would engage in it whenever $v>p e-$ apl; but since $p \ell-\alpha p \ell<x$ in this case, the problem of an excessive incentive to engage in his activity would be worsened.

Now suppose that the exercise of care would be undesirable. Then the party would never be found negligent, so he would engage in his activity if $v>0$, which is (25), meaning that the problem of an excessive incentive to engage in his activity would not be altered.

(b) Assume that the party is induced to engage in his activity, that taking care is desirable, and consider the following two possibilities.

(i) $c \leqq t$ if care is not taken. The party's expected liability will be pl - apl if he fails to take care and 0 if he takes care. Hence he will take care if

$$
\text { (26) } \mathrm{x}<\mathrm{pl}-\alpha \mathrm{p} \ell \text {. }
$$

Comparing this to (16), it is evident that he might undesirably fail to take care. (This can occur whenever gl< $\alpha$ p $\ell$ : In that event, $\mathrm{p} \ell-\alpha \mathrm{p} \ell<\mathrm{p} \ell-\mathrm{q} \ell$, so that $\mathrm{p} \ell-\alpha \mathrm{p} \ell<\mathrm{x}<$ pl - $q$ l is possible. But this means that (26) is not satisfied even though the exercise of care is desirable.) (ii) $c>t$ if care is not taken. In this case, the party's expected liability will be pl $+\mathrm{n} \beta \ell$ if he fails to take care and 0 if he takes care. Hence he will take care if 
(27) $x<p l+n \beta \ell$,

but this is clearly true, since $q \ell+x<p \ell$. Thus the party will take care. Q.E.D.

Proposition 8. The best all-or-nothing criterion is different from (and thus is superior to) a threshold probability criterion.

(The argument is omitted, as explained before.)

Proposition 9. Use of proportional liability results in the same outcome that would be observed in the absence of any uncertainty over causation.

Note. In other words, the decision regarding the exercise of care will be socially desirable, but there will be exactly the problem with excessive incentives to engage in the activity as was described at the beginning of this subsection.

Proof: From the steps in (15), it is clear that the party's expected liability would be pl if he failed to take care and care was desirable. Thus, the party's situation is precisely as initially described in this subsection, from which the result follows. Q.E.D.

II. Uncertainty over Causation: Which of Several Parties Was The Author of Harm

We will assume here that there are only two parties, A and $B$, who might cause accidents (and no natural agent). 51 The situation regarding the occurrence of accidents and whether they are seen as of ambiguous origin will be analogous 
to that in part I. However, here the analysis of legal rules will be complicated by the fact that the effects of a legal rule on parties' behavior are interrelated; for one party's behavior may influence the other party's behavior by altering the likelihood of his liability for ambiguous cases. Let us note also that we will consider two possibilities regarding the parties' relationship to each other: $A$ and $B$ may act independently; or they may act in concert. If they act independently, we will assume the outcome to be a (Nash) equilibrium, a situation such that neither party would wish to alter its behavior assuming the other's to be fixed. If they act in concert, we will assume the outcome to be that which results in the highest sum of A's and B's expected values.

A. Basic model: parties decide only whether to engage in their activities.

Let $\ell$ be as before and define the following notation.

$$
\begin{aligned}
v_{A^{\prime}} v_{B}= & \text { value to } A \text { and } B \text { respectively of engaging in } \\
& \text { their activities; } v_{A^{\prime}} v_{B}>0 ; \\
p_{A^{\prime}} p_{B}= & \text { probability of accidents caused respectively } \\
& \text { by } A^{\prime} s \text { and } B^{\prime} \text { s activities; } p_{A^{\prime}} p_{B}>0 ; p_{A}+ \\
& p_{B} \leqq 1.52
\end{aligned}
$$

Hence, it will be socially desirable for $A$ to engage in his activity if

$$
\text { (28) } v_{A}>p_{A} l \text {, }
$$

and for $B$ to do so if 
(29) $v_{B}>p_{B} l$.

If only one of the parties engages in his activity, all accidents will be assumed to be known to be caused by him. But if both $A$ and $B$ engage in their activities, cases of ambiguous origin may arise; specifically, let

$\alpha=$ probability that an accident caused by $A$ appears to be of ambiguous origin; $0<\alpha \leqq 1$;

$\beta=$ probability that an accident caused by $B$ appears to be of ambiguous origin; $0<\beta \leqq 1$.

Thus, if both $A$ and $B$ engage in their activities, the probability of an accident known to be caused by $A$ will be

(30) $\mathrm{p}_{\mathrm{A}}(1-\alpha)$;

the probability of an accident caused by $A$ but seen as of ambiguous origin will be

(31) $p_{A}^{\alpha}$;

and the analogous probabilities for $B$ will be $p_{B}(1-\beta)$ and $\mathrm{p}_{\mathrm{B}}{ }^{\beta}$. Thus, A's probability of causation in cases of ambiguous origin would be

(32) $c_{A}=p_{A}^{\alpha} /\left(p_{A}^{\alpha}+p_{B}^{\beta}\right)$

and $\mathbf{B}^{\prime} \mathbf{s}$,

(32) $c_{B}=1-c_{A}=p_{B}^{\beta} /\left(p_{A}^{\alpha}+p_{B}^{\beta}\right)$.

Assuming liability to be strict, let us first examine the threshold probability criterion. Under this criterion, the only statement to add from before by way of definition is that if both parties are liable in an ambiguous case--that is, if $c_{A}>t$ and $c_{B}>t$--then $A$ will be supposed to bear a fraction $\lambda$ of the loss and $B$, a fraction $1-\lambda$. 
Let us now prove

Proposition 10. Use of the threshold probability criterion may lead to a socially undesirable outcome. specifically,

(a) if the parties act independently, then a party might undesirably fail to engage in his activity or might undesirably engage in it;

(b) if the parties act in concert and no party would be liable for ambiguously caused accidents, then parties might undesirably engage in their activities. However, if some party (or parties) would be liable for all such accidents, then parties will engage in their activities precisely when that would be socially desirable.

Proof: (a) Suppose that $v_{B}>p_{A} l+p_{B} l$. As B would then choose to engage in his activity even were he liable for all accidents, he will definitely choose to engage in his activity. Suppose as well that if $A$ also were to engage in his activity, then $c_{A}>t$ and $c_{B} \leqq t$. Thus $A$ 's expected liability were he to engage in his activity would be $p_{A} l+$ $\mathrm{p}_{B} \beta \ell$; he would thus do so only if $\mathrm{v}_{A}>\mathrm{p}_{A} \ell+\mathrm{p}_{B} \beta \ell$; and comparing this to $(28)$, it is clear that he might undesirably fail to engage in his activity. Now suppose that if $A$ were to engage in his activity, then $c_{A} \leqq t$ and $c_{B}>t$. Then $A^{\prime} s$ liability would be $p_{A} l-p_{A} \alpha l ;$ he would thus engage in his activity if $v_{A}>p_{A} l-p_{A} \alpha l$; and comparing this to (28), it is evident that he might undesirably engage in his activity. 
(b) If the parties act in concert, they will consider four possible strategies--neither engages in his activity, $A$ alone does so, B alone does so, or both do so--and they will choose that strategy with the highest sum of values net of expected liability costs. Now if neither party engages in his activity, the sum is 0 . If $A$ alone does so, it is $v_{A}-p_{A} \ell$. If $B$ alone engages in his activity, the sum is $v_{B}-p_{B} l$. If both engage in their activities, the sum is $v_{A}$ $+v_{B}-\left(p_{A} \hat{l}+p_{B} \hat{l}\right)$ when one or both would be liable in ambiguous cases, but the sum is only $v_{A}+v_{B}-\left(p_{A} l+p_{B} l-\right.$ $\left.\left(p_{A}^{\alpha}+p_{B} \beta\right) l\right)$ when neither would be liable in ambiguous cases. (Neither being liable is possible if $t \geqq 1 / 2$; suppose, for instance, that $c_{A}=c_{B}=1 / 2$ if both engage in their activities.) Note that this statement is true regardless of the fraction $\lambda$ paid by $A$ if both happen to be liable in ambiguous cases, for the sum of $A^{\prime}$ s and B's liability in such cases will be $\ell$ independent of $\lambda$.

With this in mind, let us consider the parties' decision assuming first that neither would be liable in ambiguous cases. Then it is possible that both $A$ and $B$ would engage in their activities when it is desirable for only one (or neither) to engage in his activity. Suppose, for example, that $v_{A}=2 p_{A} l$ and $v_{B}=p_{B} l-p_{B} \beta \ell .53$ on the other hand, it is not possible that $A$ or $B$ would fail to engage in his activity when that would be desirable. To show this, observe that if it is desirable for $A$ to engage in his activity, he would certainly do so: for then if $A$ alone engages in his 
activity, the sum $v_{A}-p_{A} l$ will be positive; and the sum if both $A$ and $B$ engage in their activities minus that if $B$ alone does so will be $v_{A}-p_{A} \ell+\left(p_{A}^{\alpha}+p_{B} \beta\right) l$, which is also positive; hence either $A$ alone will engage in his activity or both $A$ and $B$ will do so. Similarly, if it is desirable for $B$ to engage in his activity, he would do so.

Now consider the possibility that one or both parties would be liable in ambiguous cases. Then if it is socially desirable for $A$ alone to engage in his activity, this will be the outcome: for if $A$ alone engages in his activity, the sum of parties' values net of liability costs will be $v_{A}$ $p_{A} l>0$; if $B$ alone engages in his activity, the sum will be $v_{B}-p_{B} l<0$; if both $A$ and $B$ do so, it will be $v_{A}+v_{B}-$ $\left(p_{A} l+p_{B} l\right)=\left(v_{A}-p_{A}^{l}\right)+\left(v_{B}-p_{B} l\right)<v_{A}-p_{A} l$; hence the sum will be highest if $A$ alone engages in his activity. similarly, if it is desirable for $B$ alone to engage in his activity, this will occur. And if it is desirable for both $A$ and $B$ to engage in their activities, this will be the outcome: for then $\left(v_{A}+v_{B}\right)-\left(p_{A} l+p_{B} l\right)$ will exceed both $v_{A}-p_{A}^{l}$ and $v_{B}-p_{B}^{l}$. Q.E.D.

Proposition 11. The best all-or-nothing criterion is different from (and thus is superior to) a threshold probability criterion.

(The argument is omitted, as explained before.)

Proposition 12. Use of proportional liability leads to a socially desirable outcome. 
Proof: Using the steps in (15), we know that A's liability will be $p_{A} l$ if he engages in his activity, regardless of whether $B$ engages in his activity; and B's will similarly be $p_{B} l$ if he engages in his activity, regardless of whether $A$ does so. Hence, if the parties act independently, $A$ will engage in his activity if and only if $v_{A}>p_{A} l$ and $B$ will do so if and only if $v_{B}>p_{B} l$, so that their decisions will be socially desirable. And if the parties act in concert, this again will be true. That is, the sum of the parties' positions will be $v_{A}-p_{A} l$ if $A$ alone engages in his activity, $v_{B}-p_{B} \ell$ if $B$ alone does so, and $v_{A}+v_{B}-$ $\left(p_{A} l+p_{B} l\right)$ if both do so. Hence, the argument given at the end of the proof to Proposition 10 applies and shows that the parties will always choose the socially desirable outcome. Q.E.D.

B. Extended model: parties decide whether to engage in their activities and, if so, whether to take care

Define

$$
\begin{aligned}
& g_{A}, q_{B}=\text { probability of accidents caused respectively } \\
& \text { by } A^{\prime} S \text { and by B's activity if care is taken; } \\
& 0<\mathrm{q}_{\mathrm{A}}<\mathrm{p}_{\mathrm{A}} ; 0<\mathrm{q}_{\mathrm{B}}<\mathrm{p}_{\mathrm{B}} ; \\
& x_{A}, x_{B}=\text { costs of care for } A \text { and } B \text { respectively; } \\
& 0<\mathrm{x}_{\mathrm{A}} ; 0<\mathrm{x}_{\mathrm{B}} \text {. }
\end{aligned}
$$


The description of whether it is socially desirable for parties to take care and to engage in their activities is analogous to that given at the beginning of part IB of this Appendix. We will assume that the conditional probabilities $\alpha$ and $\beta$ of accidents appearing ambiguous apply whenever both parties engage in their activities and whether or not care is taken. Hence, for example, A's probability of causation if both he and $B$ take care is $c_{A}=q_{A} \alpha /\left(q_{A} \alpha+q_{B} \beta\right)$; his probability of causation if he takes care and $B$ does not is $c_{A}=$ $q_{A} \alpha /\left(q_{A}^{\alpha}+p_{B}^{\beta}\right)$; and so forth.

Let us now proceed. As the proofs of Propositions will be obvious by analogy to previous arguments but will be tedious to set forth, we will merely indicate what are the applicable previous arguments.

\section{1. situation under strict liability}

Proposition 13. Use of the threshold probability criterion may lead to a socially undesirable outcome. specifically,

(a) suppose that the parties act independently. Then a party might undesirably fail to engage in his activity or undesirably engage in it; and if both parties engage in their activities, then a party might undesirably fail to take care or undesirably take care.

(b) Suppose instead that the parties act in concert. Then if no party would be liable in ambiguous cases, parties might undesirably engage in their activities and if so, they 
might undesirably fail to take care. If, however, some party (or parties) would be liable in ambiguous cases, the outcome will be socially ideal.

Proof: (a) By analogy to the proofs to Propositions $4(\mathrm{a})$, (b) and $10(\mathrm{a})$.

(b) By analogy to the proofs to Propositions 4 (a) and (b) and $10(\mathrm{~b})$.

Proposition 14. The best all-or-nothing criterion is different from (and thus is superior to) a threshold probability criterion.

Proposition 15. Use of proportional liability leads to the socially desirable outcome.

Proof: By analogy to the proofs to Propositions 6 and 12 .

2. situation under the negligence rule

Proposition 16. Use of the threshold probability criterion may lead to a socially undesirable outcome. specifically,

(a) suppose that the parties act independently. Then a party might undesirably fail to take care, and the problem of an excessive incentive to engage in the activity may be exacerbated.

(b) Suppose that the parties act in concert. Then if no party would be liable in ambiguous cases, the problems in (a) may arise. If, however, some party (or parties) would be liable in ambiguous cases, the outcome will be the same one 
that would be observed in the absence of any uncertainty over causation.

Proof: (a) By analogy to the proofs to Propositions $7(a),(b)$, and $10(a)$.

(b) By analogy to the proofs to Propositions $7(a)$, and $10(\mathrm{~b})$.

Proposition 17. The best all-or-nothing criterion is different from (and thus is superior to) a threshold probability criterion.

Proposition 18. Use of proportional liability results in the same outcome that would be observed in the absence of uncertainty over causation.

Proof: By analogy to the proofs to Propositions 9 and 12 . 
FOOTNOTES

*Professor of Law and Economics, Harvard Law School. I wish to thank Charles Nesson, David Rosenberg, Richard stewart, Arthur Von Mehren, and, especially, David Shapiro for comments and the National Science Foundation (Grant no. SES-8014208) for financial support. This article will provide the basis for a chapter in the part on torts of a book entitled $\underline{A}$ Theoretical Analysis of Law on which I am at work.

1. "Accident" will refer to any instance in which harm is done and (as the title of this article indicates) in which the remedy sought by the injured party is money damages. However, the area of law to which the analysis will seem most naturally applicable is torts, for it is here that problems of uncertainty over causation seem most often to arise.

1a. See generally the cases cited in william L. Prosser, The Law of Torts (1971) at 241 .

2. In regard to the restrictiveness of this measure of social welfare and to (what will be seen to be) the highly stylized nature of the model, the usual cautionary remark applies--that for a model to be tractable, it must be highly stylized and the measure of social welfare must be restrictive. The reader should there- 
fore not take statements of results obtained in the model in anything like a direct way as recommendations for policy or as explanations for observed fact. Furthermore (see below), some attempt will be made after the analysis of the model to say what is the model's proper interpretation in view of the probable importance of considerations going outside it.

2a. The conventional statistical and decision theoretic meaning given to the word "expected" is probabilitydiscounted. Thus, expected liability is probabilitydiscounted liability; if, for instance, a party faces liability of $\$ 1,000$ with a probability of $5 \%$, then his expected liability is $5 \% x \$ 1,000$ or $\$ 50$. See generally Howard Raiffa, Decision Analysis (1968).

3. See Prosser, supra note 1a, at 241.

3a. See the discussion of Example 3, infra.

3b. However, in the concluding comments, it will be suggested that the appeal of the proportional approach may be significantly limited by (among other reasons) its being associated with higher administrative costs than is the threshold probability criterion. See also notes 34 and 35 , infra. 
3c. Point (i) concerning the possibility of a diminished or of an extra burden of liability has been noted in much recent writing on our subject. See for example Laurence $H$. Tribe, Trial by Mathematics: Precision and Ritual in the Legal Process, 84 Harv. L. Rev. 1329 (1971) at 1350; Richard A. Posner, Economic Analysis of Law (1977) at 430-433; David Kaye, the Limits of the Preponderance of the Evidence Standard: Justifiably Naked Statistical Evidence and Multiple Causation, American Bar Foundation Research J. 487 (1982); William M. Landes and Richard A. Posner, Causation in Tort Law: An Economic Approach, University of Chicago Law School (1982) at 21-24; Steven Shavel1, An Analysis of Causation and the scope of Liability in the Law of Torts, 9 Journal of Legal Studies 463 (1980) at 494; David M. Rosenberg, The Causal Connection in Mass Exposure Cases, Harvard Law School (in process); Charles Nesson, Foundations of Judicial Proof, Harvard Law School, (1982) at 68-75. Similarly, point (iii) on the desirability of the proportional approach has occasionally been noted. See for example Landes and Posner, Nesson, and, especially, Rosenberg; and see also the references mentioned in note 29 infra.

Thus, the contribution of this article does not lie in any real novelty in respect to points (i) and (iii). (To my knowledge, however, point (ii) has not been previously stated.) Rather, it lies in the systematic 
development of the points, in the differences that are shown to exist in their significance depending on the situation under study, in the generality of the analysis, and in the proofs of the Appendix (see below).

4. Suppose for instance that the loss of a barn could either be caused by a fire set by lightning (the natural agent) or else by one started by a party. What is of analytical importance about such examples is that liability does not affect the risk due to the natural agent, or, more generally, that liability does not affect the risk due to the cause alternative to the party. Thus we will be able to interpret the model of this part as applying not only when the alternative cause is a natural agent, but also when it is associated with human behavior that would not be (much) affected by liability. (Hence, as we suggested, the model would appear to apply to the situation involving the chemical plant's emissions vs. normal exposure to carcinogenic risks like medical x-radiation; for despite being the outcome of human behavior (a decision whether to have an $x$-ray at the dentist's), the magnitude of the latter risks would not seem to be much influenced by the particulars of liability law.)

5. The assumption that a loss could not be caused by both the party and the natural agent (that the barn that 
burned due to the fire set by the party would not have burned a little later due to a fire set by lightning, or that the two fires would not have merged before reaching the barn) is made only for simplicity. Were the assumption relaxed, the results would remain essentially unchanged; see notes 6 and 11, infra.

6. This example would have to be modified were we to relax the assumption that accidents always have a single cause. Suppose for instance that the risks due to the natural agent and to the party are statistically independent, so that were the party to engage in the activity, $30 \% \times 10 \%=3 \%$ would be the risk of an accident due to both causes (either cause alone being sufficient to create the loss of 1,000$)$. Then the increment in expected accident losses due to the party would be only $27 \%$; that is, it would be less than the $30 \%$ risk he might be said to cause, and by the $3 \%$ risk of accidents that would have occurred due to the natural agent in any event. Thus it would be socially desirable for the party to engage in his activity if his benefits would exceed 270 .

This general point applies not only when the loss caused by the party would have occurred simultaneously due to another agent, but also when the loss would have occurred sometime later due to another agent (e.g., cancer due to a chemical contaminant might have occurred 
several years later due to medical $x$-radiation), or when the loss masked or accentuated a loss that occurred sometime earlier due to another agent (e.g., cancer due to the individual's smoking habit and to medical $x$-radiation is only diagnosed after, and is perhaps aggravated by, his exposure to a chemical carcinogen).

7. This is the only form of liability that is studied in the present version of the model, as there is no decision about care and hence no meaningful interpretation of negligence.

7a. In the model considered in this article there is only one type of ambiguous case and hence only one possibile level of the probability of causation. This means that under the threshold probability criterion the party is either liable in every ambiguous case or in none. In a more general model with a multiplicity of types of ambiguous case, of course, the party's probability of causation might sometimes exceed the threshold and sometimes not--so that he might be liable in some ambiguous cases and not in others.

8. We will use this $50 \%$ threshold probability criterion in succeeding examples as well, but the appendix considers all possible thresholds. 
9. See (14) and Proposition 2 of the Appendix.

10. Suppose in Example 3 that the best decision is, say, to find liability. Then those (presumably few) parties with benefits between 300 and 350 would be undesirably discouraged from engaging in the activity.

11. If we relax the assumption that accidents have a single cause, the proportional approach will continue to result in the level of expected liability that will lead the party to decide in a socially desirable way whether to engage in his activity. Suppose, for instance, that there is a $3 \%$ risk of accidents due to both the party and to the natural agent, as described in note 6 , supra; that $1 \%$ is the risk of such cases appearing ambiguous; that $18 \%$ is the risk of accidents due to the party alone appearing ambiguous (leaving a $9 \%$ risk of accidents due to the party alone being correctly identified); and that $4 \%$ is the risk of accidents due to the natural agent alone appearing ambiguous. Then, as the party's probability of causation would be derived by dividing the likelihood that he alone caused an ambiguous case by the total likelihood of ambiguous cases, it would be $18 \% /(1 \%+18 \%+4 \%)=78.26 \%$. Hence, the party's expected liability were he to engage in the activity would be $23 \% \times 782.6+9 \% \times 1000=270$. But this was explained in note 6 to be the increment in 
expected accident losses that would be created by the party's engaging in his activity. Thus the party will indeed be induced correctly to choose whether to engage in his activity.

We shall not bother to make further comments in notes showing our points to be unaffected by the possibility that accidents are due to more than one cause.

12. Specifically, if the party takes care, then the probability of causation equals $2 / 3 \times 28 \% /(2 / 3 \times 28 \%+5 \%)=18.66 \% /$ $23.66 \%=78.87 \%$.

13. That is, $2 / 3 \times 6 \% /(2 / 3 \times 6 \%+5 \%)=44.44 \%$.

14. Of course, and as mentioned, the incentive whether to engage in the activity may be appropriate.

15. This argument was originally elaborated in steven Shavell, strict Liability vs. Negligence, 9 Journal of Legal studies 1 (1980). See also, William M. Landes and Richard A. Posner, The Positive Economic Theory of Tort Law, 15 Georgia Law Review 851 (1981) at 904-916.

16. On the other hand, there can be no possibility of the party's being undesirably discouraged from engaging in the activity due to uncertainty over causation, for he can always escape liability by taking due care. (However, 
this would not be true if the party could not be sure of escaping liability by taking due care--because, say, of the possibility of error in assessing whether he took due care.)

17. This argument is developed in steven Shavell, The Judgment-Proof Problem, Harvard University (1983). Its point can be easily appreciated by reconsidering the situation where the cost of care is 10 and the exercise of care would reduce the risk created by the party from $30 \%$ to $28 \%$. If the party takes care, then under the negligence rule his only costs would be 10 , whereas if he does not take care, his expected liability would be 300, which is a much larger quantity. Thus the party would have to escape liability with very high probability to make it worth his while to act negligently. (For instance, even if he escaped liability 95/100 of the time, his expected liability would be 15 were he not to take care; since 15 is greater than 10, he would still choose to take care.)

Under strict liability, by contrast, even a moderate likelihood of escaping liablity would be enough to lead the party not to take care. (If he escaped liability, say, $2 / 3$ of the time, his expected liability would fall from 100 to 93.33 if he were to take care, so he would not wish to do so). 
18. The activities of the parties might be imagined to be of a similar type (e.g., each party might be a manufacturer of the same drug or of the same explosive), or the activities of the parties might be thought to be different (e.g., the doctor practicing surgery, the nurse assisting him, the firm producing the medical instrument). It will make no difference to the analysis which of the two interpretations is made.

19. Of course, the very meaning of the proportional approach is to apportion damages among parties in proportion to their individual probabilities of causation.

Under the threshold probability criterion, the possibility of apportionment also may arise. Suppose, for instance, that the form of liability is the negligence rule and that several negligent parties' probabilities of causation exceed the threshold. Then we might have to contemplate the possibility of apportionment among them. However, in the examples of this part of the article, we will not have to do so; we will be able to establish our results about the threshold criterion (that it has various defects) without inquiring into the effects of apportionment.

It should also be mentioned that under the moreprobable-than-not criterion, the issue of apportionment can never arise, for it is impossible that more than one party's probability of causation exceeds $50 \%$; the individual probabilities of causation must sum to $100 \%$. 
20. This is the conventional characterization of the goal pursued by parties who act in concert. The interpretation of the characterization is easily explained. Suppose that the sum of parties' positions were not maximized. Then it would be possible to make all parties better off by choosing a strategy that increased the sum and by making appropriate "side payments". Suppose, for instance, that under one strategy, party A's position is 5 and B's is 10 , whereas under a second strategy A's position is 3 and B's is 17 . Then the second strategy involves a higher sum (20 rather than 15 ) and, indeed, pursuing it allows both parties to be made better off. For example, let $B$ make a side payment to $A$ of 5--leaving $B$ with 12 , which exceeds 10 , and giving $A$, which exceeds 5 . Such mutually beneficial side payments are always possible when the sum of parties' positions is increased.

21. Recall that in Example 12, A did not engage in his activity because he would have borne an extra burden of liability of 50. But here that does not matter because the parties are envisioned to make side payments as if to compensate for disadvantages suffered or advantages gained. For instance, if $B$ were to pay $A 30$ to engage in his activity, $A$ would be induced to do so, and $B$ would prefer this to engaging alone in his activity. Specifically, A's position would be $(325-350)+30=5$, 
so he would be made better off, and B's net position would become $(125-50)-30=45$, so he too would be made better off.

22. While in Example 12, B also engaged in his activity because he in effect fobbed off 50 of his expected accident losses on $A$, here $A$ would pay $B$ not to engage in his activity. If A paid B, say, 30 not to engage in his activity, they would each be better off than if each engaged in his activity: A's position would be $400-300-30=70$ rather than $400-350=50 ; B^{\prime}$ s position would be 30 rather than $75-50=25$.

23. See Prosser, note la, supra at 241.

24. That is, given the occurrence of an accident, the probability that there will be significant doubt about its cause will usually be small. Given that my neighbor's house burns down, the probability that there will be substantial uncertainty whether the cause was the fire I set to barbecue meat or one started by lightning will be slight. Given that a pedestrian is run over, the probability that there will be substantial uncertainty whether the cause was my firm's truck or another's will be negligible. 
25. If I believe that there will be no uncertainty over causation and thus that I will face liability in the great majority of instances in which I cause harm, I will behave much as I would in the absence of the possibility of uncertainty over causation, which is to say that (other things equal) I will behave appropriately. This intuitively obvious point should be clear from our examples and discussion, and in any event, will be immediately evident from our formal analysis. (For example, as the probabilities $\alpha$ and $\beta$ that an accident caused by the party and by the natural agent would be seen as ambiguous tend to 0 , so will the likelihood of socially undesirable behavior; see the Appendix.)

26. Under the negligence rule, we showed that parties whose anticipated probability of causation in ambiguous cases would exceed the threshold will not take excessive care; it is only that they will have a specially strong motive to take due care. And we observed that although parties whose probability of causation would be less than the threshold might in theory fail to take due care, this is not likely (refer to the discussion following Example 9 and to note 17, supra).

27. See John Kaplan, Decision Theory and the Fact Finding Process, 20 stanford Law Review 1065 (1968) at 1072. 
27a. This view is perhaps best expressed and its validity most convincingly demonstrated in Wex Malone, Ruminations on Cause-in-Fact, 9 stanford Law Review 60 (1956). See in particular Malone's discussion at 72-88 of rescue of seamen, of escape from fire, of competing causes and accidental shootings, and of medical malpractice.

28. Summers v. Tice, 33 Cal. 2 d 80, 119 P.2d 1 (1948). See more generally Prosser, note 1 a supra, at 243 and at 319; and see the discussion and citations in the articles mentioned in note 29 , infra.

29. We refer here to litigation over cancer caused by the drug DES. (Millions of women used this drug during their pregnancies; this has created the risk of an often fatal cervical cancer in the women's prenatally exposed daughters; and the women have typically found it difficult or impossible to identify the producer (out of several hundred firms) of the DES that they purchased.) In an influential decision in the DES litigation, Sindell v. Abbott Laboratories $163 \mathrm{Cal}$. Rptr. 132, 607 P. 2d 924 (1980), the California supreme Court held that each defendant producer of the drug should be liable according to its share of the market, and thus ostensibly according to the probability that it sold the drug that caused the plaintiff's injury. 
This decision has stimulated much interest not only because of the importance of the DES litigation itself, but also because of the larger issues involved. See for example Comment, DES and a Proposed Theory of Enterprise Liability, 46 Fordham L. Rev. 963 (1978); Note, Market Share Liability: An Answer to the DES Causation Problem, 94 Harv. L. Rev. 668 (1981); Glen O. Robinson, Multiple Causation in Tort Law: Reflections on the DES Cases, 68 Va. L. Rev. 713 (1982); Richard Delgado, Beyond Sindell: Relaxation of Cause-In-Fact Rules for Indeterminate Plaintiffs, 70 Calif. L. Rev. 881 (1982); and David M. Rosenberg, note 3a, supra.

29a. For liability according to market share to be equal to liability in proportion to the probability of causation, all firms' shares of the market must be taken into account. Suppose that firms A, B, and C dominate the market, each holding a $30 \%$ share, and that a "fringe" of small firms sells to the remaining $10 \%$ of the market. Then A, B, and C ought each to pay $30 \%$ of damages; it would obviously be incorrect for each to have to pay $33.33 \%$ of damages; the fact that some in the fringe of small firms may be judgment proof or defunct by the time suit is brought ought not to alter the calculation of A, B, and C's market shares. 
Additionally, for use of market shares to result in liability in proportion to the probability of causation, the possibility that different firms' products might present different risks must be considered. If firm $X$ and firm $Y$ divide the market but firm $Y$ 's product is twice as risky as firm X's, then the likelihood that a loss of ambiguous origin was caused by firm $Y$ is clearly more than its $50 \%$ share of the market; the likelihood is in fact $66.66 \%$ that $Y$ caused the accident (for $Y$ causes two accidents for every one which $X$ causes). More generally, suppose that $n$ firms $i=1, \ldots$ $\mathrm{n}$ produce a total output of $\mathrm{N}$ units; that the maker of any particular unit cannot be identified; that $s_{i}$ is the share of the market of firm $i$; and that $p_{i}$ is the probability of "failure" of a unit of firm i's. Then if a unit fails, the likelihood that, say, firm $j$ was its maker equals $p_{j} s_{j} N /\left(\sum_{i=1}^{n} p_{i} s_{i} N\right)=p_{j} s_{j} /\left(\sum_{i=1}^{n} p_{i} s_{i}\right)$. (This may also be expressed as $\left(p_{j} / p_{1}\right) s_{j} /\left[s_{1}+\sum_{i=2}^{n}\left(p_{i} / p_{1}\right) s_{i}\right]$, that is, one may use "weighted" market shares, where the weights correspond to relative product risks.)

29b. In a case like summers, however, the problematic effects are only apparent; in point of fact, the adverse effects on behavior of hunters of using the usual approach would probably be negligible, for the likelihood of several hunters' bullets simultaneously hitting another must be small. 
30. For instance, in summers the court said that the injured party "has been placed. . . in the . . position of pointing to which . . defendant. . .caused the harm. If one [defendant] can escape, the other may also and plaintiff is remediless." And in sindell, the court said "In our contemporary . . . society, advances in science and technology create . . goods which may harm consumers and which cannot be traced to any specific producer . . [We] acknowledge that some adaptation of the rules of causation and liability may be appropriate in these recurring circumstances . . . The manufacturer is in the best position to discover and guard against defects in its products. . . thus holding it liable. . will provide an incentive to product safety."

31. The processes through which health-related and environmental harms come about are often complex, imperfectly understood, and of long duration. Thus, it indeed seems plausible that firms creating the risk of such harms may believe there is a substantial likelihood that the injuries they cause could not easily be attributed to them.

32. It is instructive to contrast the situation of a manufacturer of DES with respect to two types of risk: that of a cancer such as the one actually caused by 
DES; and that of a company-owned truck running down a pedestrian. As to the first type of risk, we have suggested that a manufacturer might have thought the likelihood of substantial uncertainty over causation to be high; and thus we have suggested that the adverse effect on the manufacturer's behavior of use of the usual approach rather than the proportional might be significant. But as to the second type of risk, the likelihood of substantial uncertainty over causation is undoubtedly small (as remarked in note 24, supra); and thus there would be little reason to recommend replacement of the usual approach.

32a. If the first type of error in use of market shares mentioned in note 29 a supra, is made, it is clear that dominant firms (A, B, and C of note 29a) will bear excessive liability, meaning that they might be led to take excessive care or to decide against engaging in their activity (production of the good). Conversely, the fringe firms would bear too little liability, resulting in the opposite problems.

If the second type of error in use of market shares is made--that is, if market shares are not adjusted in consideration of differences in product risks--then a peculiar dilution of incentives to take care will result. This is due to the fact that if a 
firm reduced its product risks and thereby expected accident losses by some amount, its liability would fall by only its market share times this amount. To illustrate, suppose that liability is strict (a similar (but more complex) argument can be made if liability is based on the negligence rule); that firm F and firm $G$ each command half the market; that each causes $\$ 50,000$ of losses, which cannot be directly attributed to it; and that by taking care, $F$ can reduce the losses it causes to $\$ 25,000$. Then if $F$ takes care, its liability would fall from $50 \% \times \$ 100,000=\$ 50,000$ to $50 \% \times \$ 75,000=$ $\$ 37,500$; thus F's liability falls by only $\$ 12,500$, its $50 \%$ market share times $\$ 25,000$. As a consequence, F's incentive to take care is too small; F would decide to take care only when the cost of care was less than $\$ 12,500$ rather than (as would be socially desirable) whenever it was less than $\$ 25,000$. By contrast, if the market share calculation were adjusted (as described in note 29a) to reflect alteration in product risk, F's liability would fall to $\$ 25,000$ if he took care; for as he would then cause only $1 / 3$ of the losses, his liability would be $33.33 \% \times \$ 75,000=\$ 25,000$; thus F's incentive to take care would be appropriate.

To demonstrate this more generally, use the notation from note 29a, and suppose that a firm's liability is determined by its market share $s_{i}$ and that liability is strict (and that firms act independently of one another). 
Then if firm $j$ can at a cost $x_{j}$ reduce its product risk from $p_{j}$ to $p_{j}$ ', its expected liability would fall from $s_{j}\left(\sum_{i=1}^{n} p_{i} s_{i} N\right)$ to $\left.s_{j}\left(\sum_{i \neq j}^{n} p_{i} s_{i} N\right)+p_{j} s_{j} N\right)$; thus its liability would fall by $s_{j}\left(s_{j}\left(p_{j}-p_{j}{ }^{\prime}\right) N\right)$. Hence firm $j$ would take care only when $x_{j}$ was less than this amount. But since $s_{j}\left(p_{j}-p_{j}{ }^{\prime}\right) N$ is the actual decline in expected losses associated with firm j's exercise of care, it would be desirable that it take care whenever $x_{j}<$ $s_{j}\left(p_{j}-p_{j}{ }^{\prime}\right) \mathbf{N}$. Hence, any firm $j$ will take care too infrequently (given the behavior of other firms). On the other hand, if liability is determined by use of the adjusted market shares, the incentive to take care will be correct. In strict logic, we already know this to be true, for use of the adjusted market shares results in liability in proportion to the probability of causation (and we knew that this creates appropriate incentives). Nevertheless, let us directly verify the point. If the firm takes care, its expected liability falls from $\left(p_{j} s_{j} / \sum_{i=1}^{n} p_{i} s_{i}\right)\left(\sum_{i=1}^{n} p_{i} s_{i} N\right)=p_{j} s_{j} N$ to $\left(p_{j} s_{j} /\left(\left(\sum_{i \neq j}^{n} p_{i} s_{i}\right)+\right.\right.$ $\left.p_{j} s_{j}\right)\left(\sum_{i \neq j} p_{i} s_{i} N+p_{j} s_{j} N\right)=p_{j} s_{j} N$. Thus, its expected liability falls by $s_{j}\left(p_{j}-p_{j}{ }^{\prime}\right) N$, and it will therefore choose to take care if and only if that would be socially desirable.

33. See generally Richard A. Posner, Chapter 21 note 3a, supra; John Gould, The Economics of Legal Conflicts, 2 
Journal of Legal Studies 279 (1973); and Steven shavell, suit, settlement, and Trial: A Theoretical Analysis Under Alternative Methods for the Allocation of Legal Costs, 11 Journal of Legal studies, 55 (1982).

34. There is however, a competing consideration: if the plaintiff party believes the probability of causation to be above the threshold, although he would often find it worthwhile to initiate legal action under the threshold criterion, he might not under the proportional approach-because his damages would be less than full damages. This consideration seems less important than the one mentioned in the text, for it is precisely when the probability of causation exceeds the threshold that the proportional approach does not reduce damages much below the full amount.

A formal comparison of the incentive to bring suit under the two approaches may be clarifying in this regard. Let $t$ be the threshold probability; $c_{p}$ be the plaintiff's estimate of the probability of causation; $\ell$ be the dollar amount of his loss; and $\mathrm{k}$ be the cost to the plaintiff of bringing suit. Then (i) if $c_{p}>t$, the following is true: under the threshold criterion, the plaintiff would receive a judgment (or settlement) of $\ell$, so will bring suit if $\ell>k$; under the proportional approach, he would receive $c_{p} l$, so he will bring suit if $c_{p} l>k$; hence the plaintiff will bring suit under the threshold criterion but not under the proportional 
approach if $\ell>k>c_{p} \ell$. (ii) on the other hand if $c_{p} \leqq t$, then the situation is simply that the plaintiff will never bring suit under the threshold criterion but will do so under the proportional approach if $c_{p} \ell>k$.

Thus, (iii) the claim that suit is more likely under the proportional approach amounts to a claim that it is more likely that $c_{p} \leqq t$ and $c_{p} l>k$ than it is that $c_{p}>t$ and yet $\ell>k>c_{p} \ell$.

35. To make this argument precise, let us assume that the plaintiff has brought suit and that he and the defendant will go to trial if and only if there does not exist a settlement amount which each would find preferable to going to trial. Equivalently, they will go to trial when the plaintiff's opinion of the judgment amount exceeds the defendant's by more than the sum of the trial costs that they would bear. Thus, to compare the propensity to go to trial under the two approaches, we must compare the difference between plaintiff's and the defendant's opinions of the judgment amounts under the two approaches.

To this end, let $t, \ell$, and $c_{p}$ be as in note 34 , supra; let $c_{d}$ be the defendant's estimate of the probability of causation; and let $k_{p}$ and $k_{d}$ be respectively the plaintiff's and the defendant's costs of going on to trial. Now let us consider three possible relationships that may exist between $c_{p}$ and $c_{d}$ : (i) both $c_{p}$ 
and $c_{d}$ exceed $t$. In this case, under the threshold probability criterion, there will always be a settlement, for both parties will believe the judgment to be the same; divergence of opinion about $c_{p}$ and $c_{d}$ will not matter since both are above $t$. However, under the proportional approach, there might be a trial: if the plaintiff's estimate of the probability of causation exceeds the defendant's by enough, this will be true; if $c_{p^{2}}-c_{d^{2}}>k_{p}+k_{d^{\prime}}$ there will be a trial. (ii) $c_{p}$ exceeds $t$ but $c_{d}$ does not. Here, under the threshold probability criterion, there might well be a trial, for the plaintiff will expect to win $l$ but the defendant will expect to pay nothing; in particular, there will be a trial if $\ell>k_{p}+k_{d}$. Under the proportional approach, there might also be a trial; this would be so when $c_{p} l-c_{d}{ }^{l>k_{p}}+k_{d}$. But since $\ell>c_{p} l-c_{d} l$, there would be a trial more often under the threshold criterion. (iii) $c_{p}$ does not exceed $t$. In this case, under the threshold probability criterion, there will never be a trial, for the plaintiff would not expect any judgment. But under the proportional approach, there might be a trial; and this will again be true if $c_{\mathrm{p}} \ell-\mathrm{c}_{\mathrm{d}}{ }^{\ell>\mathrm{k}_{\mathrm{p}}}+\mathrm{k}_{\mathrm{d}}$.

The implication of the preceding is this. In cases (i) and (iii)-- whenever the plaintiff's and the defendant's estimates of the probability of causation exceed the threshold or whenever the plaintiff's falls 
below it--there will be a settlement under the threshold probability criterion but there might be a trial under the proportional approach. Only in case (ii)--only when it happens that the plaintiff's estimate of the probability lies above the threshold and the defendant's lies below the threshold is it true that there is a greater likelihood of a trial under the threshold probability criterion than under the proportional approach. On balance, then, the suspicion is that the chance of litigation conditional on suit having been brought is greater under the proportional approach than under the threshold probability criterion.

35a. Equivalently, parties may generally desire to raise the likelihood of positive compensation by giving up full compensation in some circumstances. And this is an implication of the economic theory of risk aversion and insurance. See generally Kenneth J. Arrow, Essays in the Theory of Risk-Bearing (1971).

36. For recent discussions of minimization of error and the more-probable-than-not rule, see David Kaye, note 3a, supra, and James Brook, Inevitable Errors: The Preponderance of the Evidence standard in Civil Litigation, 18 Tulsa Law Journal 79 (1982). 
36a. The goal of error minimization seems closely related to principle of fairness just discussed because a high cost of error in punishing an innocent party implies that one would not wish to impose punishment unless the likelihood of guilt was great.

36b. Specifically, assuming the goal to be the minimization of error costs measured in dollar terms--that is, the number of dollars erroneously awarded plus the number of dollars erroneously not awarded--Kaye, note $3 a$, supra, showed the superiority of the more-probable-than-not rule over all possible alternative rules, and thus in particular over proportional liability. (Kaplan, note 27, supra, had earlier proved (under the same assumption) the superiority of the more-probable-than-not rule over only other probability thresholds.) The idea behind Kaye's argument (which he makes formally) showing the superiority of the more-probable-than-not rule over proportional liability is simple. It is that if we know that a defendant is more-likely-than-not the cause of harm, then on average we will do best to make him pay; to make him pay only in proportion to his probability of causation would be to fail to insist that he pay some dollars which we know on average it is best to have him pay. And conversely, if we know that a defendant is more-likely-than-not innocent of having done harm, then on average we will do best to let him go; to make 
him pay at all, or in proportion to his probability of causation, is to insist that he pay dollars that on average will have been paid by innocent parties. Suppose for instance that there are 100 cases, in each of which the defendant is believed to have been the cause with probability $60 \%$; that in 60 of these cases, defendants truly caused harm; that in 40 of these, they did not; and that the amount of harm in each instance is $\$ 1,000$. Then under the more-probable-than-not criterion, each defendant would pay $\$ 1,000$; thus in 60 cases, no errors will have been made; in 40 cases, $\$ 1,000$ will have been erroneously paid; hence the total error in dollars will be $\$ 40,000$. By contrast, under the proportional approach, each defendant would pay $\$ 600$; thus in 60 cases $\$ 400$ will erroneously fail to be paid; in 40 cases, $\$ 600$ will erroneously be paid; hence the total error in dollars will be $\$ 48,000--a$ higher error than under the more-probable-than-not criterion. In point of fact, Kaye's result can be strengthened. It turns out that whatever are the weights attaching to the two types of error--the dollars erroneously paid, and the dollars erroneously not paid--some threshold probability criterion (generally different from 50\%) will be superior to proportional liability. (In Kaye's case, the weights attaching to the two types of error were equal.)

To demonstrate this, let $w_{1}$ be the weight multiplying errors of the first type; let $w_{2}$ be the weight 
multiplying errors of the second; let $\mathrm{p}$ be the party's probability of causation; and let $\ell$ be the loss suffered. Then if the party pays $\ell$ in damages, the expected error cost in $(1-p) w_{1} l$, and if he does not pay anything in damages, the expected error cost is $\mathrm{pw}_{2}{ }^{2}$. Hence, the expected error minimizing all-or-nothing rule is to make a party pay $\ell$ whenever $(1-\mathrm{p}) \mathrm{w}_{1} \ell<\mathrm{pw}_{2} l$, or equivalently, whenever $\mathrm{p}>\mathrm{w}_{1} /\left(\mathrm{w}_{1}+\mathrm{w}_{2}\right)$, which is a probability threshold criterion. (Note that this formula implies that when the weights are equal, the threshold is $50 \%$, that when $w_{1}$, the weight of the first type of error (innocents' paying damages) is larger than $w_{2}$, the threshold exceeds $50 \%$, etc.) Under proportional liability, expected error costs are higher. Since under this approach the party pays $p l$ whatever is $p$, expected error costs are $(1-\mathrm{p}) \mathrm{w}_{1} \mathrm{p} \ell+\mathrm{pw}_{2}(\ell-\mathrm{p} \ell)$. These expected error costs exceed the error costs under the optimal threshold criterion. To see this, observe that $(1-\mathrm{p}) \mathrm{w}_{1} \mathrm{p} \ell+\mathrm{pw}_{2}(\ell-\mathrm{p} \ell)=\mathrm{p}\left[(1-\mathrm{p}) \mathrm{w}_{1} \ell\right]+(1-\mathrm{p})\left[\mathrm{pw}_{2}{ }^{\ell}\right]$ $\geqq \min \left[(1-\mathrm{p}) \mathrm{w}_{1} l, \mathrm{pw}_{2} l\right]=$ error costs with a probability threshold of $w_{1} /\left(w_{1}+w_{2}\right)$, and note that the inequality is strict so long as $\mathrm{p}$ is positive, unequal to the threshold, and less than 1.

36c. More precisely, and in the language of welfare economics, the ranking of social states ought to be a function of individuals' rankings (equivalently, the social welfare 
function ought to have as its arguments individuals' utilities). See for example Paul A. Samuelson, Foundations of Economic Analysis (1947), and Kenneth J. Arrow, Social Choice and Individual Values (1963).

36d. To repeat what has been said in slightly different terms, this anomaly arises because the cost of error criterion does not recognize the particular nature of the conseguences due to allowing firms to go free (a high level of carcinogens, no compensation of victims). But any measure of social welfare which is defined in terms of the consequences must obviously recognize them.

37. The decisions whether to engage in activities and over care will be discrete. However the qualitative nature of our results would not be altered were we to have studied a model with the levels of activities and/or the levels of care continuously variable; see notes 45 and 48 , infra.

37a. If (1) holds with equality, society will, of course, be indifferent about whether the party engages in his activity; for ease of exposition we will not comment hereafter in the Appendix on possibilities of indifference.

38. This assumption will be maintained in the other versions of the model. 
39. This is obvious. Suppose, for instance, that $p=n$. Then $c$ reduces to $\alpha /(\alpha+\beta)$, which can clearly range over $(0,1)$.

40. As remarked in note 7 supra, the negligence rule cannot be studied in the basic model because there is no variable interpretable as care. Moreover, as the court cannot observe $v$ (see following paragraph of the text), it cannot, for instance, determine if $v<p l$ and if so call a party "negligent" for having engaged in his activity.

41. This can be regarded as an implication of the criterion, for then $c=1>t$.

42. This is possible since we noted that c could range over $(0,1)$. (Hereafter, we will not bother to observe that various inequalities are possible, as this will be obvious. )

43. Note that $n \beta \ell$ is what we earlier called his extra burden of liability.

44. Note that pal is what we called the reduction in his burden. 
45. If the level of activity were continuously variable, Proposition 1 would still hold. We sketch the situation in this event. Let $z$ be the level of activity, $v(z)$ be its value (where $v^{\prime}(z)>0, v^{\prime}(z)<0$ ), and zpl be the associated level of expected accident losses. Then social welfare is given by $v(z)-z p \ell$ and the socially desirable level of activity, say $z^{*}$, is determined by $v^{\prime}(z)=p l$. Now the probability of causation $c$ is given by $c=c(z)=z p \alpha /(z p \alpha+n \beta)$, which is increasing in $z$. Let $z_{t}$ be the $z$ such that $c\left(z_{t}\right)=t$; thus $c(z)<$ $t$ for $z\left\langle z_{t}\right.$ and $c(z)>t$ for $z>z_{t}$. (If $c>t$ for all $z>0$, define $z_{t}=0$; if $c<t$ for all $z>0$, define $z_{t}=\infty$. Hence, the party's choice of $z$ will be determined by $\max \left(\max _{\mathbf{z} \leqq \mathbf{z}_{t}} z p \ell-z p \alpha \ell, \max _{\mathbf{z}>\mathbf{z}_{t}} z p \ell+n \beta\right)$. From these facts the following may easily be established: If $z^{*}<z^{\prime}$ ' then the chosen $z$ will be in between $z^{*}$ and $z_{t}$ i in particular, $\mathbf{z}$ will be higher than is desirable. If $z^{*}>z_{t}$, then there are two possibilities. One is that the chosen $z>z_{t}$, in which case $z=z^{*}$; but the other is that the chosen $z \leqq z_{t}$, in which case $z=z_{t}$ and is thus below the socially desirable level. Hence Proposition 1 is indeed true.

46. Were the threshold allowed to vary with $p, n, \ell, \alpha, \beta$, and $f(\cdot)$, then, trivially, the court could alter the threshold so as to achieve exactly the result under the best all-or-nothing criterion. (The court would merely 
choose any $t<c$ when (14) holds, and it would choose any $t \geqq c$ when (14) does not hold.) But it does not seem natural to interpret such a variable probability threshold--one which is in effect the more complicated criterion of (14)--as a threshold probability criterion.

47. A similar contradiction could be established were $c \leqq t$.

48. In the continuous case, proportional liability also results in a socially desirable outcome (as it will in the continuous case of subsequent versions of the model). Referring to the description of the continuous case in note 45, supra, we see from the steps used in (15) that the party's expected liability will equal zpl, so that he will maximize $v(z)-z p \ell$ and thus select $z^{*}$, the socially desirable $z$.

49. This seems the most natural assumption, but others are plausible. (For instance, taking care might alter the nature of accidents in such a way as to make them less easily confused with those caused by the natural agent; thus $\alpha$ and $\beta$ might fall if care were taken.) It will be clear that our analysis could easily be modified to take into account such possibilities and that this could change some of our results (in the main, it could alter the nature of the departure from the socially desirable outcome under the threshold probability criterion), but we shall not discuss this matter. 
50. We assume that there are no errors in observing $x$ or in determining whether (16) holds.

51. It will be obvious how to extend the arguments to the case with three or more parties and/or with a natural agent, but it would be cumbersome to do so.

52. Analogous to the situation in part $I$, the event that $A$ causes an accident and the event that $B$ causes an accident will be assumed mutually exclusive, etc.

53. In this case, it is desirable for $A$ alone to engage in his activity, yet if both engage in their activities, the sum of their positions will be $\left(2 p_{A} \ell+p_{B} \ell-p_{B} \beta \ell\right)-$ $\left(p_{A} \ell+p_{B} \ell-\left(p_{A}^{\alpha}+p_{B}^{\beta}\right) l\right)=p_{A} \ell+p_{A}^{\alpha \ell}$, which is positive, greater than what would be received if $A$ alone were to engage in his activity (namely $\mathrm{p}_{A} l$ ), and greater than what would be received if $B$ alone were to engage in his activity (namely, $-p_{B} \beta \ell$ ). Thus both $A$ and $B$ will engage in their activities. 